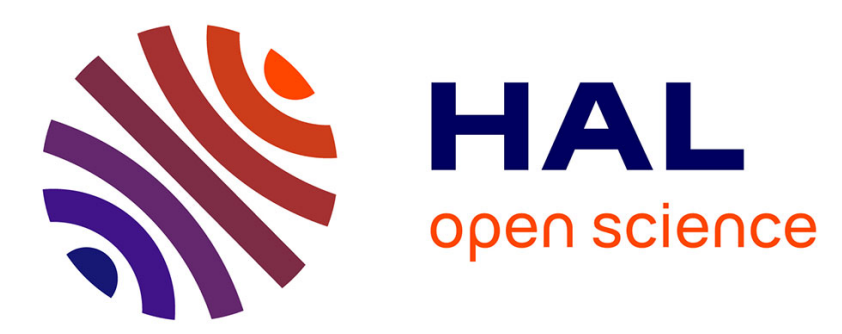

\title{
Nano-Evaluris: an inhalation and explosion risk evaluation method for nanoparticle use. Part I: description of the methodology
}

\author{
Jacques Bouillard, Alexis Vignes
}

\section{- To cite this version:}

Jacques Bouillard, Alexis Vignes. Nano-Evaluris: an inhalation and explosion risk evaluation method for nanoparticle use. Part I: description of the methodology. Journal of Nanoparticle Research, 2014, 16 (2), pp.2149. 10.1007/s11051-013-2149-5 . ineris-01709857

HAL Id: ineris-01709857

https://hal-ineris.archives-ouvertes.fr/ineris-01709857

Submitted on 15 Feb 2018

HAL is a multi-disciplinary open access archive for the deposit and dissemination of scientific research documents, whether they are published or not. The documents may come from teaching and research institutions in France or abroad, or from public or private research centers.
L'archive ouverte pluridisciplinaire HAL, est destinée au dépôt et à la diffusion de documents scientifiques de niveau recherche, publiés ou non, émanant des établissements d'enseignement et de recherche français ou étrangers, des laboratoires publics ou privés. 


\title{
NANO-EVALURIS: \\ An Inhalation and Explosion Risk Evaluation Method for Nanoparticle Use : -Part I: Description of the Methodology-
}

\author{
Jacques X. Bouillard, and Alexis Vignes, INERIS, Parc Alata, Verneuil en Halatte 60550 France
}

\begin{abstract}
1 Abstract
In this paper, an inhalation health and explosion safety risk assessment methodology for nanopowders is described. Because toxicological threshold limit values are still unknown for nanosized substances, detailed risk assessment on specific plants may not be carried out. A simple approach based on OHB/OEB (Occupational Hazard/Exposure Band) expressed in mass concentrations is proposed for nanopowders. This approach is consolidated with an Iso Surface Toxicological Scaling (ISTS) method, which has the merit, although incomplete, to provide concentration threshold levels for which new metrological instruments should be developed for proper air monitoring in order to ensure safety. Whenever the processing or use of nanomaterials is introducing a risk to the worker, a specific nano pictogram is proposed to inform the worker. Examples of risk assessment of process equipment (i.e. containment valves) processing various nanomaterials are provided. Explosion risks related to very reactive nanomaterials such as aluminum nanopowders can be assessed using this new analysis methodology adapted to nanopowders. It is nevertheless found that to formalize and extend this approach, it is absolutely necessary to develop new relevant standard apparatuses and to qualify individual and collective safety barriers with respect to health and explosion risks. In spite of these uncertainties, it appears, as shown in the second paper (Part II) that health and explosion risks, evaluated for given MWCNTs and Aluminum nanoparticles, remain manageable in their continuous fabrication mode, considering current individual and collective safety barriers that can be put in place. The authors would, however, underline that peculiar attention must be paid to non-continuous modes of operations, such as process equipment cleaning steps, that are often under-analyzed and are too often forgotten critical steps needing vigilance in order to minimize potential toxic and explosion risks.
\end{abstract}

Keywords: nanosafety, "nanosafety by design", nanotoxicity, nanoparticles, risk evaluation, control banding, accidental and chronic risk, safety barriers, collective and individual protections, Seveso major accident risks.

\section{Introduction :}

The prefix nano means a billionth $\left(10^{-9}\right)$. Nanopowders are composed of particles of primary size ranging from about 1 to 100 nanometres $(\mathrm{nm})$. Nanotechnology is concerned with the creation or manipulation of particles and materials whose minimum dimensions are nanometric, though normally less than $100 \mathrm{~nm}$ (ISO definition, (ISO/TS-27687, 2008),(ISO/TS-80004-1, 2010),(ISO/TS-80004-4;, 2011)).

While the development of nanotechnologies innovatively integrates multidisciplinary sciences, the presence of nanomaterials, both from nature and humans, dates from ancient times. Several of these processes have been known for a long time, while others are new technologies. Cooking, transportation using internal combustion or jet engines are, on one hand, operations that can unintentionally release nanoparticles into the atmosphere while, on the other hand, accidents can massively release intentionally manufactured nanoparticles in the atmosphere. Nevertheless, the potential of Engineered Nanomaterial and nanotechnologies to improve the quality of life and to contribute to economic growth and competitiveness of industry has been widely recognized. As nanomaterial production and use is going to increase (Baran et al., 2002; Cascone et al., 2002; Kipp, 2004) (Ferrari, 2005) (Gemeinhart et al., 2005; Kneuer et al., 2000; Nandiyanto and Okuyama, 2011; Ravi et al., 2004; Roy et al., 2005; Salem et al., 2003; Yoo et al., 2005), there will be more and more potential applications with their associated risks. Knowledge about the hazards related to these new materials is currently 
limited. That is why the sustained development of nanomaterial production cannot be promoted without a deeper evaluation of environmental and occupational hazards.

According to current regulation, a nanoscale substance hazard is not considered as different from that of a conventionnal microsized substance. Regulation in Europe regarding nanoparticles is based on existing laws and regulations for chemicals, namely the requirements of the REACH regulation (Registration, Evaluation and Authorisation of Chemicals), adopted by the European Union in October 2003.

The significant lack of scientific knowledge about nanoparticles risks concerning accidental, acute or chronic risks led the National Institute for Occupational Safety and Health in the USA ((NIOSH - Centers for Disease Control and Prevention, 2005), the Health \& Safety Laboratory in Great Britain ((HSE, 2004) and the Health and Consumer Protection Directorate of the European Commission (SCENIHR, 2005) the National Institute of Research about safety at workplaces in France (Witschger and Fabries, 2005a, b) and other organizations ((INNOVEST, August 29, 2005)) to conduct literature reviews in order to determine the state-of-the-art about occupational health and safety hazards related to nanoparticles and risk analysis methodologies.

For the last thirty years, most companies have developed their own home-grown control banding risk analysis in which a ranking matrix (hazards, probability/exposure) is considered to rank risk score. This has been the case for pharmaceutical industry who routinely deals with highly toxic powders that can be, in some cases, made of nanoobjects. In such analysis, usually 5 Hazard bands are considered (very low, low, medium, high and very high). When the toxicity of a material is unknown (as for example for nanomaterials), the highest risk ranking is considered with the highest hazard and highest exposure scores. In such evaluation, no distinction is made between a highly toxic nanoobject and a highly toxic microobject, they have both the same highest ranking but as we know, they behave differently and so they should necessitate distinct types of prevention and protection measures. In 2010, ANSES proposed a tool for control banding risk assessment by considering a hazard band depending on the toxicity of the substance and an exposure band depending on the emission potential of the substance, whether the substance is presented as a solid, liquid, powder or aerosol form(ANSES, December 2010). In the ANSES approach, various risks are evaluated, (dermal, ingestion, inhalation...), for which, as discussed above, five main classes hazard band ranking (HB1, HB2, HB3, HB4, and HB5) are retained as originally proposed in the COSHH and other methodologies. Other control banding tools have been proposed and have been recently reviewed by Zalk (Zalk and Nelson, 2008), Fleury (Fleury, 2011) and Brouwer (Brouwer, 2012). In his paper, the latter investigator summarized these few control banding tools as the Precautionary matrix(Hock, 2008), Nanotool (Paik, 2008), ANSES (ANSES, December 2010), StoffenmanagerNano(Marquart, 2008; Van Duuren-Stuurman, 2012), Nanosafer (http ://nanosafer.i-bar.dk), and Guidance(Cornelissen, 2011).

In Stoeffenmanager control banding, nanoobject emission factors depend on the type of operations considered that are termed as "operations with very unlikely release or small or very small amounts", or as "handling products at low speed, or as "with little force in medium quantities", or as "at relatively high speed that may lead to some dispersion of dust", or as "high speed, high force, or large quantities of generated dust"....). The interpretation of these operation descriptions remains somewhat vague in addition to their control band risk score which depends on intrinsic properties of the materials (i. e. fine granule, flakes, coarse dust, fine dust, extremely fine dust). It is clear that in such operations, complex factors pertaining to the nanopowder come into play.

We can however discern that the quantity of nanomaterial used is often considered as a key parameter in such analyses, (i. e.; 1 to100 mg(Groso, 2010)). As mentioned by Groso, whenever the extent of toxicity of a chemical substance is insufficiently known, the 
Precautionary Principle resolution should apply (Groso, 2010). To circumvent these uncertainties related to nanopowder handling, we devised an approach in which 7 classes of inhalation occupational mass based exposure concentration bands (OEB) are considered because, as will be seen later, the inhalation exposure threshold limit values (TLVs) for nanoparticles are usually smaller than those for microparticles. Through these mass based TLVs, process emission factors can be more easily evaluated and so the collective or individual safety barriers more easily chosen based on their specific performance. Unlike other control banding approaches which usually independently deal with various risks (inhalation, dermal, ingestion, fire and explosion), the methodology described in this paper only pertains to inhalation toxicity and explosion/fire risks, which are common nanoparticle risks encountered in industry. In other words, eye, skin or ingestion toxicological routes or other ecotoxicological routes are not being considered here in an effort to streamline as much as possible such type of analysis.

3 Main steps of the proposed risk assessment methodology:

\subsection{Two Types of Risks to Consider: Chronic and Accidental}

In this section, the general risk assessment methodology related to health and explosion risk assessment is reviewed. Because of the current lack of toxicological data on nanoobjects, health risk methodology will be briefly explained whereas explosion risk assessment will be more detailed. Major accident risks are not presently considered. However, as will be noticed our risk assessment approach can easily be extended to take into account Seveso accident major risks (Seveso Directive).

Occupational safety usually deals with the whole range of incidents or accidents which can cause harm to personnel. It concerns long term (sub-chronic and chronic) human exposure and short-term (sub-acute and acute/accidental) exposures, as well as accidental risks as schematically shown in Figure 1 . In an accidental risk scenario, one can consider that the potential danger (i.e. effects of explosion, fire, or dispersion) can impact operator through the use of an accidental probability and effects developed over a short period of time (the time of the accident). In contrast, in a chronic risk scenario, exposures of humans to toxic materials may last over longer periods of time (Figure 1).

From most European occupational risk methodologies, the following general steps can be summarized, as shown in Figure 2. They are based on:

- Identification of the different workplaces and the workers that can be harmed,

- Hazard identification and typology,

- Evaluation of the hazards, (based on basic safety parameters), accident probabilities, and exposure frequency,

- Risk ranking strategy (i.e. via control banding strategy) leading to risk decisions on action priorities to be taken (such as prevention, protection or mitigation actions),.

- Risk Management resulting in putting in place necessary organizational and technical barriers and continuously monitor the performance of the barriers (This step goes beyond just the risk control banding approach described here). 
To assess the specific health risk (i.e; second box in Figure 2), the methodology mainly consists in four important steps as illustrated in Figure 3:

1. hazard identification: The hazard can be a toxic agent or a set of conditions that has the potential to cause adverse effects to human health or to the environment.

2. dose-response assessment: Toxicological dose dependant effects are evaluated through the use of threshold limit values (TLVs).

3. exposure assessment, which consists on the determination of the magnitude, frequency, duration of exposure to workers.

4. risk characterisation: the toxicology and exposure data are combined to obtain a quantitative or qualitative expression of risk. Risk is the probability that individuals or the environment will suffer adverse consequences as a result of an exposure to a toxic substance.

From this figure, it is seen that for a given substance, even if dose-response effects of a substance are unknown, the major risk reduction can be achieved by nanoparticle exposure reduction. This can be accomplished essentially through dilution, extraction, filtration techniques that can be either made collectively or by using individual protective equipments (e.g. masks or other personal equipments).

\subsection{Review of Main General steps in accidental risk assessment methodology:}

In the case of accidental risk assessment, the evaluation of the hazard risk from acute exposures and/or incidents follows several steps (Figure 4 ), for which the notion of accident probability is introduced. We will note that such concept is somewhat different from the exposure frequency usually used in chronic risk assessment (Figure 3), in the sense that it refers to an accident probability, whose root causes are usually unknown, while exposure can usually be either controlled or known. These necessary steps of the methodology are described below:

1. Provide a brief description of the equipment and chemicals used in the plant is provided.

2. Identification of any hazard. Hazards that may occur in a chemical plant could include fire, toxic release, equipment fallout or collapse, corrosion, explosions, rupture of a pressurised vessel, and runaway reactions.

3. List the events or series of events that will initiate an accident has to be identified. An event could be a failure to follow correct safety procedures, an improperly repaired equipment, or a safety mechanism failure.

4. Evaluation of the accident probability. For example, in a chemical plant with a given life time, one may assess what is the probability that the temperature in a reactor will exceed the specified temperature range? The probability can be ranked from low to high. A low probability means that it is unlikely for the event to occur in the life of the plant. A medium probability suggests that there is a possibility that the event will occur. A high probability means that the event will probably occur during the life of the plant.

5. Evaluation of the severity of the consequences of the accident (damage to the material surroundings or to the persons) 
If the probability of the accident or the severity of its consequences are low, then the risk can usually be deemed acceptable and the plant should be allowed to operate. If the probability of occurrence is too high or the damage to the surroundings is too great, then the risk is usually unacceptable and the system needs to be modified to minimize these effects.

4 Application of the General Risk assessment methodology to health risks induced by nanoparticle Handling and Processing:

The proposed methodology is constructed to include both health and accidental (explosionfire) risks. The last type of risks has been voluntarily separated because the approach and the basic data needed to handle such risks are significantly different from those involved in health risks. The following section will specifically focus on the health risks issued from nanoparticles.

\subsection{Main steps to assess health risks related to nanoparticles:}

For the case of nanoparticles, the health risk assessment for accidental (acute) as well as chronic (long-term) worker exposure, can be performed by following the general procedure detailed in the previous section. In general, OECD factors (OECD, 2008)should be evaluated, some of them are underlined below.

1. First, hazards must be determined by identifying all the working unit of the industry (use, storage...) and hazards associated to each working unit.

2. Product specifications (physical chemical properties) must be given:

- The chemical composition of the nanoparticles including formulation components and impurities, surface chemistry, acidity/basicity, redox potential, reactivity (redox, photoreactivity...) and the nature of any surface coating or adsorbed species.

- The particle size range (and distribution) to which humans could be exposed, along with information on other physical characteristics, e.g. shape, density, surface area and charge, solubility, porosity, roughness morphology, crystallinity and magnetic properties.

- The extent to which the released particles are soluble in aqueous media. This is likely to be a major factor in limiting their accumulation and biopersistence in living organisms...

3. Worker exposures have to be assessed:

- Identification and quantification of relevant exposure (routes, frequency, duration and levels of exposure).

- Determination of the absorption of the nanoparticles by the appropriate route(s) of exposure at relevant doses and dose rates, including all possible translocation routes.

- Identification of the metabolic fate. This may include the characterization and quantification of nanoparticles in body tissues.

- Examination of the potential for bioaccumulation following repeated exposure to the nanoparticles.

- Susceptibility or health sensitivity of persons at work with respect to nanoparticles.

4. Dose-response relations should be assessed: 
- If possible, in-vitro/in-vivo toxicokinetics data following inhalation exposure, so that target organs can be identified and local dose-responses determined.

- In vivo data on inhalation exposure (from model animal data used for humans) to confirm previous toxicological models.

As often is the case, most of the dose-response relationships and inhalation TLVs are unknown. So, in the following, we will describe a risk evaluation technique based on a control banding approach. Such approach is based on the assumption that for a process under a normal operation, one can put in place an equipment that ensures a nanoparticle concentration level below occupational threshold limit levels in the workplace. Usually, such methodology does not take into account the cases of accidental risks, for which a particular analysis and method (i.e. fault \& consequence tree) should be applied.

The final step of the health risk assessment consists in determining adequate and reliable safety barriers to prevent harm to workers. Proposed safety barriers will be discussed in section 4.3.3.

\subsection{Main Specific steps in the evaluation of the risk due to inhalation of nanomaterials:}

The evaluation of the risk due to inhalation takes into account the hazards of the nanoparticle chemistry and the exposure conditions. The exposition can be estimated through the following steps (Figure 5):

$>$ The quantity and type of nanomaterials being processed

$>$ the physical and chemical properties (dispersability, agglomeration, reactivity...),

$>$ the conditions of the process (temperature, pressure, emission factors, quantity used...),

$>$ the potential occupational or accidental exposure scenarios (frequency/ probability of exposure)

$>$ the use of collective protections (ventilation, extraction...), or individual protection equipments.

The methodology of the evaluation of the risk due to inhalation needs the following important quantification steps:

- determination of the score assigned to a hazard class based on OEL values (Occupational Exposure Limit values) or a Occupational Band Level (OEB)

- determination of the process emission factor that will be function of the quantity, the percentage of nanopowder (if mixed with coarser powders), the degree and strength of the agglomerates, the process conditions (temperature and pressure).

- The probability of accidental release (for accidental risk evaluation) or the frequency of use for the case of chronic risks,

- determination of the classes of collective protection (i.e mechanical ventilation, a fume hood, fully protective cubicle, clean rooms, See Section 4.3.3...),

All these parameters will help determine the Individual inhalation risk severity score $S_{\text {inh }}$ (see section 4.3.2) 
Toxic hazards can be evaluated by expressing the hazard as a function of a hazard index (OHB) defined as follows:

$$
\text { Hazard }=10^{(\mathrm{OHB})}
$$

In which the OHB traditionally refers to the occupational exposure band (OEB), which usually also ranks in a scale varying from 0 to 5 . So the toxic hazard can vary from a scale ranging from 1 à 100 000, which corresponds to the TLV (Threshold Limit Values) of chemicals that may vary in the same proportions.

It has also been customary to rank the substance by its ability to induce local and systemic effects as well as specific effects such as mutagenicity, cancerogenicity, or sensitizing effects. Target organs sometimes are referred to in cases of eye and skin irritations. Such dangers have been summarized through the risk phrases of the substance (see directive EC/98/24) that have been upgraded in the new GHS classification.

The quotation of OEB for these products has been essentially made in terms of mass concentration as it is common to find the OEB developed for micro-aerosols, ranked as a function of the mass particle concentration.

\subsection{Discussion on the role of Particular Nanoparticle Metrics in Toxic Risks}

Three important metrics have been put forward to assess nanoparticle toxic risk. These are,

- the particle number per volume or $\# / \mathrm{m}^{3}:(\mathrm{N})$,

- the surface concentration $\mathrm{m}^{2} / \mathrm{m}^{3}:\left(\mathrm{C}_{\mathrm{s}}\right)$

and

- the mass concentration $\mathrm{g} / \mathrm{m}^{3},\left(\mathrm{C}_{\mathrm{m}}\right)$

For manufactured particles in a particular process, the particle size or the specific surface is often known because it is usually one of the major product specifications. This is not usually the case in most environmental pollution scenarios. This makes the problem easier because, in this case, all these metrics are somehow related.

For example we can write $\mathrm{C}_{\mathrm{m}}$, the mass concentration, as:

$$
\mathrm{C}_{\mathrm{m}}=\mathrm{N} \rho 4 / 3 \pi(\mathrm{dp} / 2)^{3} \quad \text { Équation } 1
$$

$\mathrm{C}_{\mathrm{s}}$, the surface concentration, and, $\mathrm{S}_{\mathrm{Bet}}$, the specific surface $\left(\mathrm{m}^{2} / \mathrm{g}\right)$ are evaluated as:

$$
\mathrm{C}_{\mathrm{s}}=\mathrm{N} 4 \pi(\mathrm{dp} / 2)^{2} \text { or } \mathrm{C}_{\mathrm{s}}=\mathrm{N} \mathrm{S} \text { Betp }
$$

Where $\mathrm{S}_{\mathrm{Betp}}$ is a particle surface (measured by the BET technique).

Hence the mass and surface concentrations can be related to the particle number concentrations and the mean particle size. One can draw the following parameter pairings (Table 1) that can be used as metrics in risk evaluation studies:

From this table, it is seen that the most relevant metrics is based on the number concentration $\mathrm{N}$ and the particle diameter $\mathrm{d}_{\mathrm{p}}$. Furthermore, if the density is known, the combination of number concentration/particle size metrics becomes equivalent to the mass concentration metrics. Note that in this simplified approach, we do not consider particle size distributions but mere mean particle sizes (Recall that nanoscale is defined as $\mathrm{d}_{\mathrm{p}}<100 \mathrm{~nm}$ ).

These expressions show that the concentration in mass, surface or number are related once the critical parameters of the powder (mean particle size, specific surface, particle density...) are known, and therefore, it is strongly advised to carefully characterize nanoparticles before any risk assessment studies. 
Based on the need to further define OEB scale for nanoparticles, surface metrics is an important factor to consider as shown by Oberdorster et al .(Oberdoester et al., 2005), who compared toxic effects based on surface metrics (figure 6) of powders of $\mathrm{TiO}_{2}$ of two different particle sizes. His study clearly showed that inflammatory responses depend on the surface of the particles in contact with the cells.

To ensure oneself that indeed nanoparticles could be more harmful than microparticles, a very simple $\mathrm{pH}$ test can be carried out. For example, one can perform $\mathrm{pH}$ mass titration for example with $\mathrm{TiO} 2$ micro and nano particles, using a very elementary $\mathrm{pH}$ laboratory experimental setup as shown below in Figure 7. Such pH effects can be easily measured by carrying mass titration measurements using a $\mathrm{pH}$ meter. As the particle size decreases, the solution becomes more acidic at the same solids concentration. $\mathrm{TiO}_{2}$ micro particle suspensions yield a pH of about 5 while $\mathrm{TiO}_{2}$ nanoparticle suspensions can yield an acidic $\mathrm{pH}$ of 2.5-3 (Veronesi et al., 2002; Veronesi et al., 1999), depending on the solids concentrations. These titration curves show that toxic effects (stronger acidity of nanoparticles) can be exhibited when compared to the micro particles since it is usually known that at typical acidic pHs, definite acute irreversible and reversible toxicities have been demonstrated for common acid gases such as $\mathrm{HCl}, \mathrm{H}_{2} \mathrm{~S}, \mathrm{HF}$. It is the belief of the authors that similar acidity effects could also result with the use of nanoparticles at equivalent concentrations. This hypothesis should however be further experimentally verified for the case of nanoparticles. This example just reinforces that particle size or surface is an important parameter to take into account.

From two particle sizes, one can express the surface concentration $C_{s}$ from the mass concentration $C_{m}$ as follows. If one considers two global surfaces, $S_{1}$ and $S_{2}$, one can write:

$$
\mathrm{C}_{\mathrm{s} 1}=\mathrm{N}_{1} \pi \mathrm{dp}_{1}{ }^{2} \text { or } \mathrm{C}_{\mathrm{s} 1}=\mathrm{C}_{\mathrm{m} 1} \pi \mathrm{dp}_{1}{ }^{2} /\left(\rho 4 / 3 \pi\left(\mathrm{dp}_{1} / 2\right)^{3}\right) \text { or } \mathrm{C}_{\mathrm{s} 1} \approx \mathrm{C}_{\mathrm{m} 1} / \mathrm{d}_{\mathrm{p} 1}
$$

and similarly for a same substance of a particle diameter $\mathrm{dp}_{2}$

$$
\mathrm{C}_{\mathrm{s} 2}=\mathrm{N}_{2} \mathrm{dp}_{2}{ }^{2} \approx \mathrm{C}_{\mathrm{m} 2} / \mathrm{d}_{\mathrm{P} 2} \text {. }
$$

Hence, for a same nanoparticle surface cell covering concentration $\left(\mathrm{C}_{\mathrm{s} 1}=\mathrm{C}_{\mathrm{s} 2}\right)$ of two different particle sizes , $\left(\mathrm{dp}_{1}\right.$ and $\left.\mathrm{dp}_{2}\right)$, leading to a same given toxicological effect intensity (See Figure 6), two mass concentrations, $C_{m 1}$ and $C_{m 2}$ should be considered . These two concentrations are linked by the following relation $\mathrm{C}_{\mathrm{m} 1} / \mathrm{d}_{\mathrm{p} 1}=\mathrm{C}_{\mathrm{m} 2} / \mathrm{d}_{\mathrm{P} 2}$. One could call this relationship an Iso Surface Toxic Scaling (ISTS) relationship because the surface concentration $C_{s i}$ is kept constant for two particle sizes of the same substance providing the same toxicological effect. This relation assumes self-similarities of bulk/surface properties (i.e morphologies and reactivities). Hence, the resulting threshold limiting values of mass concentrations of the same chemical substance would thus vary as $d_{p}$ ( since $C_{m} / d_{p} \approx c t e$ ), notwithstanding that along this particle size variation, the biological systemic targets could effectively be different (specific nanotrafficking routes), as was shown for the case of inhaled nano $\mathrm{TiO}_{2}$, for which direct transport of nanoparticles to the brain tissues have been recorded ( (Wang et al., 2008a; Wang et al., 2008b)). In addition, specific transport phenomena (i.e. translocation) related to nanoscale objects are systematically eluded in such an approach. Nevertheless, such type of approach remains useful in providing safety engineers with hints of nano TLVs from micro TLVs when no toxicological data at nanoscales are available. Whenever the self similar scaling rule does not apply, direct case-by-case toxicological experiments should be considered to assess the hazards of such powders. As new TLVs data are available from toxicologists, one should then take them into account. 
From the above ISTS method, mass based TLVs of smaller particle sizes are smaller than those of larger particle sizes, and hence depicting nanoparticles as more toxic on a mass basis. If we assume roughly that a representative respirable particle diameter is of the order of -say 1 $\mu \mathrm{m}$ - , for $100 \mathrm{~nm}$-nanopowders the mass concentration threshold ratio would be of 0.1 , ratio that we would keep for scaling down the nanoparticle TLV mass concentration. So as a rule of thumb, one would get the following conversion (Table 2).

It is important to realize that for a given mass per unit of volume or mass concentration, the micropowder TLVs, when scaled to nanopowders (ie Table 2), can easily be reached in workplaces where nanoparticles are processed and handled. Hence, current micropowder risk based analysis of work places should systematically be reviewed for the case of nanopowders and suitable safety barriers be provided accordingly.

Note that for soluble powders as the substance eventually ends up as a molecular solute, a micro TLV may apply for nanoparticles. However, the dissolution dynamics is usually not known, and for this reason, it is preferable to use the rule of thumb for nanopowder, that is to reduce the TLV by a factor of 10 for nanoparticles. Note also, that for nanoparticle smaller than $100 \mathrm{~nm}$, this ratio can be larger, (i.e. 100 or two decades for $10 \mathrm{~nm}$ particles with respect to $1 \mu \mathrm{m}$ particles).

This reasoning warrants the extension of the classical microscale OHB/OEB scales (0-5) to 6, and 7 or two additional decades in TLVs, as shown in Table 3, because, in the case of nanoparticles, TLVs of nanoparticles can be much smaller than those of microparticles. We should emphasize here again that proper OHB values of a given nanoparticulate substance should be accurately determined by toxicity studies and by a full agreement emanating from a panel of renown toxicologist referees. The approach developed here give us only hints of bulkpart TLV that could be inferred from micropowder TLVs assuming self similar surface and bulk properties when no toxicological data are available at the nanoscales . We will note that for EOB 6-7, the particle concentration in air becomes so low that there may not currently be any on-line instrument able to measure such low concentrations. Though, it is often possible though off-line measurements. We feel though, that because technological progress will further advance metrology, that such limits will soon be easily measured.

Note that recently, NIOSH proposed for nanoparticles of $\mathrm{TiO}_{2}$ a $\mathrm{TLV}$ of $0.3 \mathrm{mg} / \mathrm{m}^{3}$, which would represent a low hazard according to this table $(\mathrm{OEB}=1)$. These proposed values comfort the ISTS method. TLVs for $\mathrm{TiO}_{2}$ microparticles are of the order of $4-5 \mathrm{mg} / \mathrm{m}^{3}$. From the above approach, for $100 \mathrm{~nm} \mathrm{TIO}_{2}$ (See Table 2), the resulting TLV would be such as $\mathrm{TLV}_{\text {micro }} / 10$ or about $0.4 \mathrm{mg} / \mathrm{m}^{3}$, which thus yields, in turn, a concentration close to that recommended by the NIOSH (i.e; $0.3 \mathrm{mg} / \mathrm{m}^{3}$ ).

This table is also useful to provide hints of ranges of concentrations that metrologists would have to consider so as to develop proper instrumentation to ensure safety in production work places. We observe that such nanoparticle TLV concentrations can be very low for highly potent substances. It is important to write down such concentrations because it gives information on how low the detection levels of the instruments used as monitoring tools in a safety barrier have to be. Once this is known, then engineers will have to develop such instruments and push research and technology at least and beyond to such limits. Currently, such limits pose serious technological questions for metrology engineers. The main difficulty lies in the current lack of proper instrumentation that can detect such low concentration 
thresholds from a (so-called natural) background containing natural nanoparticles. Such lack of instrumentation providing chemical speciations remains a major challenge in nanosafety. We will see however that for such low concentrations, the use of clean rooms/laminar flow booths may then be valid solutions. In fact, in some cases, simple solutions can rely on combinations of techniques as discussed later in the following sections.

Fibrous nanoobjects are not directly considered in this approach. However, in the asbestos case, TLV is defined in number concentration, namely 0.1 fiber/cc (Toxnet, NIOSH) or 1.0E5 fibers $/ \mathrm{m}^{3}$, (note that Broekhuizen proposed 0.01 fibers $/ \mathrm{cm}^{3}$ (Peter Van Broekhuizen, 2012; Van Broekhuizen et al., 2012)). If this TLV is applied to nanotubes (assuming $12 \mathrm{~nm}$ diameter and 20 microns of length), this would lead to concentrations of the order of $1 \mathrm{ng} / \mathrm{m}^{3}$ $(\mathrm{OEB}=6-7)$. Not knowing the exact toxicity of nanotubes, though some studies have suggested that they could behave like asbestos, the threshold limit value of asbestos for nanotubes could be retained for our analysis. We should realize that contrary to asbestos, CNT (carbon nanotubes) can be relatively easily oxidized and decomposed as was shown by INERIS (Elgrabli et al., 2008), which may not be the case for other types of mineral nanotubes. For the case of CNT nanotubes, NIOSH recommended a REL (recommended exposure limit) at workplaces of about $7 \mu \mathrm{g} / \mathrm{m}^{3}$ Note that this resulting threshold limit is about the one commonly used now in epidemiologic studies for environmental pollution (i.e; $\approx 2-10$ $\mu \mathrm{g} / \mathrm{m}^{3}$ or an OHB of about 3-4), well below the commonly used TLV for ordinary non toxic microscale dust (10 mg/m $\mathrm{m}^{3}$ for inhalable dust and $4-5 \mathrm{mg} / \mathrm{m}^{3}$ for respirable dust). We reemphasize that for precautionary motivations, two new OHB (6 and 7) are constructed because, it is very likely that future OHB limits for some unknown nanoobjects may fall within that range. At present, it is clear that such so low ranges may not bear strong toxicological significance, just already from the stand point related to the lack of experimental means needed to measure and monitor such low concentrations at workplaces. This being said, in practice in the use of these bands, one would call upon an ALARA (as low as reasonably achievable) principle rather than invoking a full precautionary principle.

In the following, to keep it simple, we will consider only the mass concentration and particle number concentration when needed. The particle size is supposed to be known or measured; when unknown we assumed it to be $100 \mathrm{~nm}$.

\subsubsection{Proposed Pictograms indicating the presence of Nanoparticles in a product or at work places}

In a workplace or on a product, a pictogram (Figure 8) signaling the presence of nanoparticles (that can potentially be suspended in air as the result of its use) could be proposed. Placing this pictogram in a certain work environment would require to perform a risk analysis so as to make sure that the potential concentration, be it in the case of chronic or accidental exposure modes, may not exceed the toxic threshold level. Placing this pictogram on a particular product or in a particular work environment would depend on the potential nanoobject released concentrations, its release rate, and its toxicity (i.e; OHB).

With this in mind, this pictogram would make aware operators or general users of products containing nanomaterials of the danger associated by the potential presence of nanoparticles that can be released in the atmosphere.

\subsubsection{Concepts of the methodology: Hazard Severity and Risk Definitions}

The concept of the inhalation risk assessment methodology for nanomaterials is shown in Figure 5. One of the first parameter, as often forgotten in classical risk analysis at 
professional settings, is the quantity of the product used in the process. The particle size distribution is important since TLVs depend on particle sizes. To make it simple, we will only consider the percentage of particles smaller than $100 \mathrm{~nm}$. Agglomeration is also a parameter of importance since we know that this phenomenon plays a role in defining TLVs, as being notified as a key factor by the OECD in risk evaluation. For the time being, we will consider that the nanosize quantity under consideration, given by the main quantity * \% of nanopowder which does not agglomerate (as a conservative scenario). Once these elements are known, a process emission factor Iproe, which depends on the process considered can be assessed. In some instances, equipment suppliers provide such values, but in most cases they have to be evaluated either experimentally or computationally through the use of mathematical dispersion models (See companion paper, Part II).

The hazard index of the nanopowder is provided through TLVs or OHB/OEBs values. Two types of safety barrier indices (collective and individual) can be provided and have their own index (Iprotc and Iproti). Such indices can be experimentally evaluated and are often given by the barrier manufacturer. All these elements are used to provide information on the severity of the risk in an index called Is. Accidental probabilities or normal use frequencies concerning a process are integrated into a frequency index If.

In our approach, the inhalation risk severity is defined as

$\mathrm{S}_{\text {inh }}=$ Hazard $\times$ Process emission / Collective protection Score /Personal Protection Score Équation 2

Or in terms or indices as

$$
10^{\text {Is }}=10^{\text {OHB }} \times 10^{\text {lproe }} / 10^{\text {lprotc }} / 10^{\text {lproti }}
$$

Équation 3

or equivalently, the Severity index Is can be then evaluated

$$
\text { Is= OHB }+ \text { Iproe }- \text { Iprotc }- \text { Iproti }
$$

\section{Équation 4}

Where Iproe is the process emission index, while Iprotc and Iproti are respectively the collective and individual protective Indices (see later). For example, for a given nanopowder of an OHB of 2, if the emission concentration in the workplace is ranging between 100-1000 $\mu \mathrm{g} / \mathrm{m}^{3}$, the process emission index Iproe is of the order of -2 , meaning that the severity index Is, if no collective or personal protection measures are taken, is zero: In other words, the emission factor is within the TLVs (OHB) of the substance. Typical examples of Iproe factors evaluated for containment valves will be discussed in section 4.3.3.

The risk can be defined by a combination of the severity and the probability/frequency of the event as

$$
\mathrm{R}=\mathrm{S}_{\mathrm{inh}} \times(\text { Accidental Probability or frequency of use })
$$

\section{Équation 5}

Which can be recast as

or equivalently leads to

$$
10^{\text {Ir }}=10^{\text {Is }} \times 10^{\text {If }}
$$

$$
\text { Ir }=\text { Is }+ \text { If }
$$


Where Ir is the risk index, Is the risk severity index, and If the frequency index, so that the risk index appears as the combination of the severity index Is and the accidental probability or use frequency index If.

Note that the time basis of an OHB/OEB is usually a working day or 8 hours. We can thus construct the following Table 4 for the exposure or frequency index for times shorter than 8 hours.

Note that in all these developments, we force ourselves to express the severity or the risk as powers of ten. This makes it easier to evaluate risk reduction factors. It is noteworthy to realize that, in accidental cases, process emission factors can be very large but at the same time the exposure times can be very short. We also note that the If scale follows very roughly the time reduction factors. Behind this approach, the concept of the dose (concentration* exposure time $=$ constant) is apparent (Berge et al., 1986; Bunce and Remillard, 2003).

The severity is being considered as acceptable whenever the severity Index, $\mathbf{I}_{\mathbf{s}}$, is zero or negative. Note that in that case, the risk index is also zero or negative. In some cases, the chronic risk can be reduced by imposing small exposure times. This can be managed through what is called organizational risk management reduction techniques. A zero or negative risk index can be considered as then acceptable.

Thus, without going into further details, the following acceptability criteria used here are:

\section{Acceptable (Risk or Severity): if Ir or Is $<=0$}

The Process emission factor (Iproe) depends on the process equipment, the quantity of the powder used and the percentage of nanoparticles present in this powder that can be released and dispersed in air. Often times, we use a mix of powder with only a percentage of nanoparticles used as additives. Agglomeration can reduce the amount of airborne nanoparticles. In fact, the cohesion energy of these agglomerates is a critical factor controlling the process of desagglomeration into primary particles. INERIS is currently conducting studies to develop methodologies to measure particle cohesion/agglomeration energy that would enter as an agglomeration scale index in the risk analysis (see Figure 5). From past experience, highly dispersive nanopowders generating large quantities of suspended nanoparticles, as well as poorly dispersive nanopowders for which very low levels of released and resuspended nanoparticles may exist in real situations. The methodology should therefore take into account all these ranges of variation.

From Equation 4, it is seen that for a toxic material (high and positive OHB), the process emission factor should be forced to be small enough (highest negative value) to yield a zero severity index. In other words, for toxic materials, one needs to reduce as much as needed the emission of nanoparticles through confinement technologies through collective or individual protection equipments.

\subsubsection{Examples of Typical Types of Prevention/ Protection Barriers: a) Containment Equipment used in the Pharmaceutical Industry with their associated Emission factors}

Typical evaluation of emission factor, Iproe, in the pharmaceutical industry, process emission factors have been evaluated for some type of containment technologies, namely highly tight connection valves. For information, some examples are given below, drawn from GEA 
Pharma Systems. For such systems, the emission factors are sometimes quantified and are mentioned below. A proposed Iproe scale for such equipment is given as shown in Figure 9. Split Valves of high containment performance of various nominal sizes are currently proposed in systems processing nanomaterials. Each type of valves has its emission factors which have been evaluated by the supplier as shown above. A more detailed discussion on the evaluation of $\mathrm{I}_{\text {proe }}$ of a given process will be provided in Part II companion paper.

Once the process emission index Iproe is evaluated for a given process equipment, the resulting risk severity index Is, described earlier for a given toxic substance (OHB), can be assessed and deemed as either acceptable or not acceptable.

\subsubsection{Examples of Other Types of Prevention/ Protection Barriers: b) Collective and Personal Equipments}

Supplemental proper collective and individual protection methods should then put in place so as to reduce the risk, in cases of high severity indices, for which the confinement process alone is not sufficient. These measures can rely on the use of clean rooms (with their ISO classification) or high performance personal protection Equipment (PPE) such as respiratory face masks, ventilated equipment, self contained breathing apparatus SCBA, that could also be used in emergency scenarios (See Figure 10). Similarly, one can evalutate protection efficiency of these types of suits considered in Figure 10 as shown in Table 6 Note that these tables just given to illustrate the methodology. In practical cases, the real qualification and quantification of the protective equipment should be performed.

From these protective suit performances, one can evaluate residual risks for a given type of suit. The final choice of the personal equipment, however, will greatly depend on the toxicity of the substance and the type of collective equipment already put into place.

5 Application Example of the Control banding methodology

Assume a process that uses a bulkvalve HC, whose local emission index is given in figure 8 . There is no specific collective extraction and filtration equipment used in this process. The plant manager wishes to know what kind of personal equipment should workers wear when processing nanopowders (100 nm size) of a substance for which the TLV of $1000 \mu \mathrm{g} / \mathrm{m}^{3}$ is known as a micropowder?

\section{Solution:}

From table 2, the TLV for the $100 \mathrm{~nm}$ nanopowder would be of the order of $100(\approx 1000 / 10)$ $\mu \mathrm{g} / \mathrm{m}^{3}$ which yields an OHB (occupational hazard band) of about 2 .

The Severity index, Is, for this piece of processing equipment (bulkvalve HC) can be estimated as :

$$
\begin{gathered}
\text { Is }=\text { OHB }+ \text { Iproe }- \text { Iprotc }- \text { Iproti } \\
\text { Is }=2-2-0-0=0 \leq 0
\end{gathered}
$$

So the safety of the process is satisfactory. No specific protection barriers are needed for use in normal operations. However, abnormal or accidental situations should be studied in particular. Proper protection equipment should then be provided to the workers, should such a situation occur. 
We also notice that if one were to process a more dangerous substance, for example a substance with an OHB of 5 or 6 , the severity index could be of the order of about $5-2=3$, $>0$ thus posing a risk to the workers. In such a case, specific and stricter collective or individual protection measures should be provided to the workers. At least P3 masks or nonventilated suits should be provided to the workers all the more so as the substance displays additional types of risks. In all cases, even more stringent precautions should be assessed should accidents or abnormal situations occur. In such accident analyses, typical scenarios are evaluated using bow tree (fault/consequence tree) diagrams (See Figure 11 for a typical case of nanopowder handling in an industrial site) from which proper safety measures are devised to counteract such scenarios (Fleury, 2011). More comprehensive details of the proposed approach willl be further explained in a companion paper.

For additional information, it is noteworthy to evaluate the quantity of materials that could possibly be deposited on a garment or a plate. If one assume a surface of $1 \mathrm{~m}^{2}(1 \mathrm{~m} * 1 \mathrm{~m})$, with a deposit of agglomerated of nanoparticles of about $1 \mu \mathrm{m}$ thick (with a surface covering factor of about $2.5 \%$ ), one would obtain the following mass (density of 3 assumed)

$$
\mathrm{M}=0.025 * 1 * 1 * 1 \mathrm{E}-6 * 3 \mathrm{E} 12 \mu \mathrm{g}=75 \mathrm{mg}
$$

One can estimate the resulting concentration in a workplace when these $75 \mathrm{mg}$ are released as a spontaneous source. To make it simple, if one assumes that this mass is released in a bedroom of about $20 \mathrm{~m}^{3}$, one would obtain a residual concentration of about $3.7 \mathrm{mg} / \mathrm{m}^{3}$, which is quite high for interior air quality standards, especially if the particle material is considered as being toxic. This explains why work clothes should always be kept at work and not brought at home.

Another interesting aspect of this calculation, is its relevance to cleaning processes. If one wants to clean equipment that has been in contact with nanopowders, one should be very careful to make sure than limited amount of residues remain on the container walls so as to provide a minimal potential release into the environment. From these observations, it is also clear that during the cleaning stages of a process, workers should be protected accordingly.

6 Reduction of emission factors by the use of "Nanosafety by design" Concept

In this new concept, an effort is made to formulate or introduce the potentially harmful nanoobjects into a matrix containing such nanoobjects to prevent them to be easily released, thereby contributing to the reduction of the emission factor and hence the inhalation risk.

Few examples can already be cited in this direction: The development of Metal Matrix Composites (MMC), Polymer Matrix Composites (PMC), and some foam matrices. An example is given below for CNT incorporated into polyamide PA6, product commercially termed as "masterbatch granules". So in essence, we change the problem of a highly fluffy and pulverulent material (MWCNT) (left of Figure 13) into one for which the emission factor is close to zero at moderate aggressive stresses (See right of Figure 13). The final product is in the form of millimeter size granules (Right of Figure 13) that can be integrated into a final polymeric product.

In such cases, process emission factors (Iproe) are negligible of the order of -9 or -10 , which thus reduce the risk for any type of toxic materials (See Equations 2, 3 and 4 ). In other words, the risk ( hazard $\mathrm{x}$ emission) can be as low as wished, thus making the downstream process somehow intrinsically safe. One should however be guarded against the thought that no release is possible. Recently, Bouillard and his colleagues have shown that for this type of "safer by design" materials, under certain aggressive conditions, release of MWCNT is possible. This has been the object of a new patent describing new means to measure such 
release (Bouillard, 2011) and to evaluate the emission factor when the material is subject to aggressive stresses.

7 Fire and Explosion risk assessment methodology for nanoparticles:

7.1 Fire and Explosion Safety parameters related to nanopowders:

Explosion hazards of nanopowders have received little attention to date. To explode, nanopowders have to be combustible. So far, literature studies concerning the evaluation of explosion and flammability risks of powders were essentially carried out for micron-sized materials and there is still an unknown as far as the increase of hazards due to explosible nanopowders.

\subsubsection{Main Conditions for the Occurrence of nanodust explosion:}

There are a few basic rules to observe to see whether a dust can generate a dust explosion in a given volume. They are summarized in what is called: the Hexagon of Explosion (Figure 14). It consists of the following conditions:

- $\quad$ The dust must be combustible.

- The dust must become airborne.

- The dust cloud must be confined.

- The dust concentration must range within the explosible range.

- An ignition source must be present.

- The atmosphere must contain sufficient comburant such as oxygen to support and sustain combustion.

\subsubsection{Main parameters affecting nanodust explosions:}

\subsubsection{Dust chemistry:}

Dust chemistry is one of the fundamental considerations when investigating dust explosions. It directly influences the thermodynamics and the kinetics of the reaction, which in turn affect the severity of the explosion.

\subsubsection{Moisture and relative humidity:}

The moisture works in three main ways. The heating and evaporating the moisture provides an inert heat sink which prevent combustion from propagating. Once evaporated the water vapour mixes with pyrolysis gases for example and makes them less reactive. Water vapour can also increase intermolecular cohesion of the dust introducing larger effective particle sizes and increasing sedimentation.

Moisture content of a dust will affect the ability of a dust cloud to be ignited and its ability to sustain an explosion. Increased moisture content usually requires larger explosion ignition energies and reduces explosion severities. However, with some metal dusts such as aluminum dust, increasing moisture may lead to more violent explosion due to hydrogen production (Dufaud et al., 2005; Traoré et al., 2009). 


\subsubsection{Particle Size and Specific Surface area}

Dusts with particle size above $420 \mu \mathrm{m}$ ((NFPA, 1962) are not causing dust explosion. This upper limit can range from $200 \mu \mathrm{m}$ or $500 \mu \mathrm{m}$ as reported by Laurent ((Laurent, 2003). No clear lower particle size limit, below which combustible dust explosions cannot occur, has ever been established. Effects of specific surface area of carbon blacks and aluminum particles with respect to explosion severity were studied by Bouillard (Bouillard et al., 2010) who showed that after passing through a maximum, the explosion severity tends to decrease,. Such trends are thought to be governed by agglomeration/aggregation behaviors impacting explosion characteristics (Bouillard et al., 2010).

\section{- Influence of particle size on organic dusts:}

Often organic dust will become more and more explosive down to a certain size limit at which it will plateau. For coal, (Eckoff, 2003) reports that the limiting particle size, below which there is no further increase in the maximum explosion pressure or the rate of pressure rise, is about $50 \mu \mathrm{m}$. (Peukert W., 1996) shows a plateau at a particle size of roughly $50 \mu \mathrm{m}$ for flour, about $40 \mu \mathrm{m}$ for methylcellulose, and polyethylene, but for PVC no sign of 'plateauing' was reported.

The reason why surface area affects the violence of explosion is that particle size/surface area influences the speed at which volatiles are extracted from the particle (or how fast the particle vaporises) before they burn. In the case of a dust explosion involving organic materials, pyrolysis or devolatisation always precedes combustion, which primarily occurs in the homogeneous gas phase. The limiting particle size, below which the combustion rate of the dust cloud ceases to increase, depends on the ratios between the time constants of the three consecutive steps of devolatilisation, gas phase mixing and gas phase combustion. Particle size primarily influences the devolatilisation rate - a higher specific area allowing faster devolatilisation. Therefore, if the gas phase combustion is the slowest of the three steps, increasing the devolatilisation rate by decreasing the particle size will not increase the overall combustion rate. For materials yielding gaseous pyrolysis products that are more reactive than the volatiles from coal, one would expect the limiting particle size to be smaller than for coal, which turns out to be the case. Natural organic products, such as starch and protein, have a limiting particle size of the order of $10 \mu \mathrm{m}$ and for reactive dusts like organic dyes, this limit could even be smaller.

For carboneous particles (carbon blacks), Bouillard showed the existence of two combustion regimes (Bouillard et al., 2010): A kinetically controlled regime at very small particle sizes, and a diffusion controlled regime at larger sizes, explaining the occurrence of more severe explosions for smaller particle sizes.

- Influence of particle size on metal dusts:

For metal dusts, especially the more reactive metals like aluminium and magnesium, the limiting particle size should be even smaller than that for organic dusts. No limiting size data could be found in the literature, but a plot of rate of pressure rise against specific surface area for aluminium (Eckoff, 2003) shows the rate still increasing at a specific surface area of $6.5 \mathrm{~m}^{2} / \mathrm{g}$. This would correspond to mono-sized spherical particles of $0.34 \mu \mathrm{m}$ in diameter. The reason for such low size is that the reaction steps for a metal dust explosion are different from those involved in pyrolyzing substances thus rate limiting steps are different. Metal particles do not devolatilise or pyrolyse, but melt, evaporate and burn as discrete entities. Bouillard showed that for aluminum particles, there also exists two combustion regimes, a 
kinetically controlled regime at small sizes and a diffusion controlled regime at larger sizes (Bouillard et al., 2010). This observation explains the nanosized particle explosion severity increase is due to not only the mere increase of particle specific surface, but also to the change of the combustion regime (shift from a diffusion controlled to a kinetically controlled regime), and effectively, nanosized aluminum particles experimentally displayed more violent explosion characteristics than their microsized counterparts.

- Influence of the minimum explosion concentration:

The variation of lower explosion limit (LEL) with particle size also exhibits a plateau. The LEL is taken as the lowest dust concentration at which an ignition can be achieved. A plot given by Eckhoff ((Eckoff, 2003)) shows for low volatile coal the limiting particle size is about $20 \mu \mathrm{m}$ (LEL of about $150 \mathrm{~g} / \mathrm{m}^{3}$ ), for high volatile coal about $50 \mu \mathrm{m}$ (LEL of roughly $130 \mathrm{~g} / \mathrm{m}^{3}$ ) and for polythene about $80 \mu \mathrm{m}$ (LEL of roughly $50 \mathrm{~g} / \mathrm{m}^{3}$ ). It should be noted that the limiting particle size at the LEL is not necessarily the same as the limiting value obtained at higher dust concentrations, where the explosions are more violent. Bouillard explained through the use of a simplified model, the existence of such limits for small particle sizes (Bouillard et al., 2010).

- Influence of the particle size on the oxygen concentration:

The limiting particle size, at which the influence on the LEL begins to plateau, also shows a dependence on oxygen concentration. For coal ((Eckoff, 2003)), reducing the oxygen concentration from the $21 \%$ in air to $15.5 \%$ reduces the limiting particle size from about $50 \mu \mathrm{m}$ to $15 \mu \mathrm{m}$. Increasing the oxygen content to $50 \%$ increases the limiting particle size to about $100 \mu \mathrm{m}$. As would be expected the actual value of the LEL decreases as the oxygen concentration is increased.

- Influence of the particle size of the minimum ignition energy:

The available data ((Eckoff, 2003)) on the influence of particle size on the minimum ignition energy (MIE), ie the minimum energy required to ignite the dust cloud, indicates a very strong dependence, a near exponential relationship, with no obvious 'plateauing' of the relationship even at particle sizes down to a few microns. A theoretical treatment developed by Kalkert and Schecker (Kalkert and Schecker, 1979) predicts that the MIE is proportional to the cube of the particle diameter. Experimental results given in Eckhoff ((Eckoff, 2003)) for polyethylene powder are in agreement with this predicted relationship. The polyethylene data covers a particle range of 25 to $250 \mu \mathrm{m}$ - the MIE increasing from 10 to $3000 \mathrm{~mJ}$ over this range of sizes. Bouillard showed that there is a change in the dependency of the MIE with respect to the particle size which is the direct result of the change of combustion regime (shift from a diffusion controlled regime to a kinetically controlled regime) for nanosized particles with no plateauing limit effects (Bouillard et al., 2010). At very low particle sizes, the MIE can reach very low values (of the order of $1 \mathrm{~mJ}$ ). Note that for comparison purposes, the MIEs of stoichiometric hydrocarbon/air mixtures are typically of the order of $0.25 \mathrm{~mJ}$.

- Influence of particle size of electrostatic charge build-up:

Electrostatic charges can build-up on powders during transport, handling and processing. The charging tendency of highly insulated powders observed in industrial operations does not 
depend much on the composition of the powder, but more on the operations performed and the specific surface area of the powder ((Glor M. , 1988)). The charging tendency has been found to drastically increase with increasing specific surface area. For example log-log plots of charge to mass ratio vs specific surface area for various organic powders show a near linear relationship. Nanopowders, because of their large specific surface areas, may become strongly charged and may provide their own ignition source if the powder is dispersed to form an explosible cloud.

\subsubsection{Dust Concentration :}

Dust cloud explosions can only occur if the dust concentration is within certain limits. The largest explosion severity cases are usually when the dust concentration is close to the stoechiometric concentration. Upper concentration limits are dictated by the minimum amount of oxygen needed for explosion, lower limits by the minimum quantity of particles needed to sustain combustion. In general the lowest concentration of dust leading to a dust explosion is around $30-100 \mathrm{~g} / \mathrm{m}^{3}$ while their maximum concentration is seldom determined. These limits are dependent on the chemical nature of the particle, the particle size distribution, the ignition energy, the shape and volume of the explosion vessel. Thus, limits obtained from the literature or experiments must be analyzed carefully.

\subsubsection{Turbulence}

A more turbulent cloud would result in a more severe explosion as the flame front will move more quickly through the dust cloud, because the turbulence provides a more homogeneous concentration.

However, dust clouds with a high level of turbulence would probably not be ignited at energies above the MIE, because of increased heat/convection dissipation due to turbulence.

Explosion maximum pressures seem to be independent on turbulence intensity whereas the maximum rate of pressure increases are strongly dependent on the turbulence intensity. In practice, it is very difficult to characterize turbulence but it can be carried done through Plexiglas sphere and by using Doppler velocimetry. (Dahoe et al., 2001)

\subsubsection{Degree of Dust Dispersion :}

Dispersion and degree of agglomeration affect the combustion as they change the effective local dust concentrations and the effective particle size respectively. A more dispersed dust will burn more easily. The degree of dispersion is usually dependent upon the method of dust dispersion and the turbulence in the system.

\subsubsection{Oxygen Content}

Lower oxygen concentrations in air cause the explosion to be less severe as it limits the rate of combustion of the dust. Generally speaking, fire can only be sustained if oxygen concentration is greater than $10-15 \%$ in air but everything depends on the chemical composition of the particle or on the presence of an other comburant). Inerting gas such as $\mathrm{N}_{2}$ and $\mathrm{CO}_{2}$ can be used to reduce or stop the particle combustion under the condition they do not react with the dust (as could be the case for metallic powders).

\subsubsection{Initial Dust Cloud Temperature :}

At higher initial temperatures, the dust cloud is more easily ignited and the minimum dust concentration required for explosion is lowered. However, the maximum explosion pressure is lowered and it is difficult to conclude for the maximum rate of pressure evolution according to ((Eckoff, 2003)). Bouillard showed that the MEC (minimum explosion concentration) 
become smaller as the temperature increases, indicating that the explosible system becomes dangereous.

\subsubsection{Initial Pressure of Dust Cloud :}

A significant increase of the pressure in a dust cloud makes the explosion more violent, essentially because all the comburant is compressed ((Eckoff, 2003)). Conversely, vacuum also lowers the explosion severity. Higher pressures lower the required ignition energy. However, too high a pressure may prevent good dust dispersion and promote agglomeration of nanopowders and then the explosion severity could result to be lower.

\subsubsection{Ignition energy requirements:}

The ignition energy must be high enough to ignite the dust particles. The parameter usually used as a measure of the ease of ignition of a dust cloud is the minimum ignition energy (MIE), which is defined as the lowest electrical energy stored in a capacitor which upon discharge is sufficient to ignite the most easily ignited dust cloud. Typical MIE values for dusts are in the range of 1 to $1000 \mathrm{~mJ}$. Recently, Bouillard showed that nanopowders have a specific combustion regime (a kinetically controlled regime) that strongly affects safety parameters such as MIE, indicating that specific measures of prevention, mitigations and protection should be taken (Bouillard et al., 2010).

\subsection{Main characteristics of the Risk Assessment Methodology:}

A new methodology for nanoparticles risk explosion can be developed mainly by taking into account the ATEX 99 (Atmopheres explosives) guidelines (1999/92/EC; 1999) and the specificities of nanopowders.

For nanoparticles, the explosion risk assessment can be performed by following the general procedure detailed in the previous section. First, hazards must be determined by identifying all the working unit of the industry (use, storage...) and all the hazards associated to each working unit. Secondly, for each working unit, the explosion risk is assessed by taking into account of 4 parameters:

$\checkmark$ The severity of the explosion

$\checkmark$ The probability of explosion which combines both:

$\checkmark$ The probability of formation of an explosive dust cloud

$\checkmark$ The probability of ignition of an explosive dust cloud

$\checkmark$ The vulnerability of the target which is associated to the presence of workers in a given plant or workshop, at a given phase of the process,

$\checkmark$ The existing safety barriers (prevention, protection and organizational measures).

These four parameters enable to determine a risk score. A risk score can be attributed by the following equation:

Risk score $=$ Severity x Probability x Vulnerability / (Risk reduction Barrier factor) Équation 6

The vulnerability factor can be evaluated by the combination of the number of workers and by the existing measures of risk reduction. This equation is very similar to Equation 5 presented in the previous toxic risk assessment section. In the simplified approach presented in this 
paper, the vulnerability is expressed as a function of the presence of the workers in the workplace, as will be later discussed.

This global approach is summarized in Figure 15 and will be detailed in the following sections.

\subsubsection{Determination of the severity of the risk:}

The severity of the risk can be evaluated by taking into account of the quantity of product and of explosion characteristics of the nanopowder. The quantity of nanoparticle is a parameter which is not specifically mentioned in the classic ATEX method(1999/92/EC; 1999). In fact, absolute quantities seem to be more adapted in our case. Based on the previous work of Vignes (Vignes et al., 2012), a new classification is proposed in the Table 7.

Note that higher score could be constructed if the amount of nanoparticles used exceed $3 \mathrm{Kg}$, (TNT equivalent mass), in such case, the explosion hazards are just becoming greater .For the purpose of this paper, we will limit the methodology to $3 \mathrm{Kg}$, which is representative of laboratories and small pilot plants.

The explosion characteristics of the nanopowder can be related to the explosion violence Kst of the nanoparticle used in a given working unit. A classical classification based on the St classes of powders is summarized in the Table 8 (1999/92/EC; 1999) and a new classification for nanopowders is proposed as shown in Table 9.

For microsized powders, this parameter can easily be obtained by the 20L sphere (Bouillard et al., 2010). Currently, the same apparatus is used to assess the violence explosion of nanopowders. It is thought that this apparatus may give reliable results to assess explosion risks of nanopowders usally present as agglomerates, as they usually are previously stored in a reservoir and then blowed into the explosion chamber. For the case of non-agglomerated nanoparticles obtained in a production process operating in dilute solids phases, such results obtained this way may be inaccurate. In fact, it can be shown, by considering a thin flame model, that Kst depends on the maximum explosion pressure Pmax, and on a fundamental kinetic parameter often represented by the fundamental flame velocity. This flame velocity depends on the surface area which is available for oxygen combustion. Therefore, it can be concluded that it is necessary to consider a nanoparticle agglomeration index as well as the theoretical available surface area to correctly assess the explosion violence, which should be the object of future work. For the time being, current standardized explosion severity protocols are being used in this paper. Taking into account the quantity of nanopowders and the violence of explosion, a severity score - ranging from 1 to 50 - can be evaluated using this methodology. The main steps leading to the determination of a severity index are summarized in Figure 16.

\subsubsection{Determination of the probability of an explosion occurrence:}

The probability of explosion occurrence in a given workplace can be evaluated by taking into account the probability of formation of an explosive atmosphere and the probability of ignition of this explosive atmosphere. 
The occurrence probability of the formation of an explosive atmosphere in a given workplace is related to the ATEX zones (1999/92/EC; 1999). The minimum explosive concentration (MEC), the nature of the process (i.e the way nanopowders are handled or produced) as well as the behaviour of nanopowders in air, enable to determine the probability of occurrence of a nanodust cloud. By taking into account of these parameters, a qualitative probability of an ATEX formation can be attributed to a work unit, which is a potential ATEX zone, by considering the following classification in Table 10 (1999/92/EC; 1999):

After having identified the ignition source enabling to ignite a nanodust cloud, the probability of the presence of an ignition source can be determined with respect to the classification proposed by INRS and CNPP for chemical risks, which can be considered as a modified and more accurate classification than the one usually employed in the classic ATEX method. This classification is showed in Table 11. In this table, situations in which the ignition source is always present are ranked as high scores.

In order to identify active and passive ignition source, it is necessary to determine the minimum ignition energy (MIE) and the minimum ignition temperature (MIT) as these parameters represent the ability of the dust cloud to be ignited (Bouillard et al., 2010). In particular, if a source of ignition presents an ignition energy greater than MIE or a temperature greater than MIT, this source is classified as an active ignition source. On the contrary, a source is qualified as a passive source if this source is not being able to ignite the medium. MIT and MIE (figure 17) are therefore parameters can be easily obtained by means of classic experiments. However, the validity of these current apparatuses when applied to nanoparticles has not been determined yet. Agglomeration and increased available reactive surface area influence safety parameters as was shown by Bouillard (Bouillard et al., 2010).

The main steps leading to the determination of a semi-quantitative probability of explosion occurrence are summarized in Figure 17. Taking into account of the occurrence of the formation of an explosive atmosphere and of the probability of the presence of an ignition source, the score of the probability of the explosion ranges from 1 to 15 .

\subsubsection{Determination of the target vulnerability: Presence of worker at work places:}

If an explosive atmosphere happens to occur in given workplace and during a specific process phase, a risk score is calculated by considering the vulnerability factor, which depends on the presence of the workers. This vulnerability factor is defined in Table 12.

We thus consider that the risk (with regards to the workers) become nil whenever workers are not present (no impact on workers). Note that this evaluation of the vulnerability towards the worker will be improved in further versions of Nano-Evaluris, taking into account worker human factors, his training and/or skills, his knowledge and understanding about risks and prevention/protections measures that can lead to either increased or decreased vulnerability indices.

\subsubsection{Determination of the impact of risk management measures through safety barriers:}

At this step of the elaboration of the explosion risk assessment methodology, it is necessary to evaluate the performance of identified safety barriers in order to assess the real probability of the dangerous phenomena. This approach is briefly presented below because it can be used for an occupational risk assessment (Delvosalle et al., 2006), (Gowland and Richard, 2006) and(de Dianous and Fiévez, 2006). 
It must be kept in mind that currently the effectiveness of the technical prevention and protection barriers is not specifically evaluated in this section. Note that technical barriers that are efficient to prevent and protect micropowder explosion scenarios may be irrelevant in the case of nanopowders.

Four main categories of safety barriers are defined in order to facilitate the assessment of the influence of safety management system on such barriers.

1. Passive barriers: barriers always in functioning (permanent), no need to human actions, energy sources and information sources. Passive barriers may be physical barriers (retention bins, walls,...), permanent barriers (corrosion prevention systems) or inherently safe design.

2. Activated barriers: These barriers set up preconditions that need to be met before the action can be carried out. So these barriers must be automated or activated manually to work or these barriers can be mechanical barriers that require an activation (hardware) to achieve their function. Activated barriers always require a sequence of detection diagnosis - action. This sequence can be performed using hardware, software and/or human actions.

3. Human prevention/protection actions: The effectiveness of these barriers is relied on the knowledge of the operator in order to reach the purpose. Human actions are to be interpreted broadly, including observations by all senses, communication, thinking, physical activity and also rules, guidelines, safety principles.... Human actions may be part of a detection - diagnosis - action sequence.

4. Symbolic barriers (or hazard warning barrier): These barriers need an interpretation by a person in order to achieve their purpose. The typical example can be passive warnings (like keeping out of prohibited areas, opening labelled pipes, refraining from smoking,...)

Once safety barriers have been identified and integrated in a safety analysis diagram (i.e. the bow-tie diagram showing the root causes and effects), it is necessary to assess the influence of these barriers on the probability of the critical cause event. The performance of a safety barrier is defined according to three parameters:

- Its level of confidence linked to its probability of failure on demand. The level of confidence of a safety barrier is the probability of failure on demand to perform properly a required safety function according to a given effectiveness and response time under all the stated conditions within a stated period of time. Actually, this notion is similar to the notion of SIL (Safety Integrity Level) defined in IEC 61511 for Safety Instrumented Systems that can be applied here to all types of safety barriers.

- Its adequate capacity to take the required action (specific size or volume, physical strength, etc.) or effectiveness. The effectiveness is the ability for a technical safety barrier to perform a safety function for a duration, in a non degraded mode and in specified conditions. The effectiveness is either a percentage or a probability of the performance of the defined safety function. If the effectiveness is expressed as a percentage, it may vary during the operating time of the safety barrier. For example, a valve which would be not completely closed on safety demand would not have an effectiveness of $100 \%$.

- Its response time. The response time is the duration between the starting time of safety barrier actuators and their complete achievement. This response time is a critical factor to evaluate the effectiveness of the safety.The direct use of the methodology proposed in the ARAMIS project (Delvosalle et al., 2006; Salvi and Debray, 2006) in order to assess the 
performance of the safety barrier is difficult at the moment because of the lack of learning experience from past accidents coming from nanotechnologies.

Thus, for simplicity in our methodology, a safety barrier risk reduction score based on the barrier confidence level was considered. Such a ranking is proposed in the following table 13: Details on the construction and evaluation of safety barriers can be found in (Le Nguyen et al., 2008). The use of these factors are used as risk reduction barrier factors in Equation 6, to reduce the explosion risks.

\subsubsection{Risk ranking}

The methodology developed in this section enables one to provide a final risk score (Equation 6) to rank the risks taking into account various accidental probabilities and explosion hazards. Such a determination of a risk score related to the explosion of nanopowders at a given working unit is used to characterize the action priorities. The prioritization of the action plans can be established via the priority table 14 which would result in specific prevention, protection and remediation actions.

Following the order of priority, actions must be taken to reduce the risk to an acceptable level (for example below the lowest priority level). Actions can consist in elimination of the presence of large concentrations of explosible nanoparticles at workplaces, substitution of nanoparticle by an another less harmful type, modification of the process equipment, its operating mode, and installation or reinforcement of technical and organizational safety barriers or improvement of the risk reduction management at the source.

\section{Conclusions:}

This paper summarizes a health and safety risk assessment methodology tailored to the manufacturing and use of nanomaterials by workers. Because toxicological threshold limits values are still unknown for nanosized substances, detailed risk assessment on specific plants can not be carried out. A simple approach based on OHB/OEB (Occupational Hazard/Exposure bands) expressed in mass concentrations was proposed to provide bands for inhalation toxic TLVs (threshold limit values) of nanopowders. When unknown, such TLVs can be inferred using an Iso Surface Toxicological Scaling (ISTS) method, and although approximate and incomplete, it has the merit to provide concentration levels at which new metrological instruments should be developed to ensure safety by reduction of exposure levels. Collective safety barriers can be designed and scaled for risks evaluated by the control banding methodology presented here. In addition, accidental risk scenarios (i.e. fire and explosion) for a given process should always be considered and resulting additional (usually personal) safety barriers should then be put into place, supplementing the collective safety barriers.

In order to formalize this approach, it appears that it is absolutely necessary to develop relevant standard apparatuses and qualify safety barriers with respect to the health and explosion risks of nanopowders. Several tentatives in this direction are being promoted (for example the certification Nanocert by INERIS (www.ineris.fr)). Because of paper limitations, the illustration of this methodology to industrial cases could not be treated in this short paper and a companion paper is being drafted in this respect. From past industrial experience, however, is has been shown that peculiar attention should be paid on non-continuous modes of operations, such as process equipment cleaning procedures in order to implement good health and safety levels and minimize risks. We also note that this methodology can easily be 
extended to major risk analyses of Seveso sites (Seveso Directive) in the sense that scaling hazard parameters, such as the mass of the substance- parameter, usually retained for Seveso plant classification, are already taken into account in this methodology and can easily be further extended to larger nanoparticle processing systems.

Acknowledgements:

This work was conducted as part of the EU FP6 funded project NANOSAFE 2: Safe production and use of nanomaterials (NMP2-CT-2005-515843), Subproject 4, Health, Societal and Environmental aspects. We would like to express our gratitude to all members of the SP1, SP2, SP3 and SP4 of this project who brought stimulating discussions over risk assessment associated to safety issues.

Nano-Evaluris: is a methodology for Evaluating Risk based on a Control Banding Approach. A first version (V0) is presented in this paper that will be improved as more scientific knowledge on toxicity and accidental hazards will be available. A second part of this paper (Part II) will illustrate how these principles can be applied to large scale industrial cases. Because of length, this paper has been split into two parts.

\section{Nomenclature:}

\begin{tabular}{|c|c|}
\hline$C:$ & carbon \\
\hline CNTs: & carbon nanotubes \\
\hline $\mathrm{C}_{\mathrm{m}}:$ & particle mass concentration $\left(\mathrm{g} / \mathrm{m}^{3}\right)$ \\
\hline $\mathrm{C}_{\mathrm{s}}$ : & particle Surface concentration $\left(\mathrm{m}^{2} / \mathrm{g}\right)$ \\
\hline$d_{p:}$ & particle size (m) \\
\hline Kst: & Explosion violence index (bar.m.s s $^{-1}$ ) \\
\hline m: & Mass of solids (Kg) \\
\hline MEC & Minimal Explosion Concentration $\left(\mathrm{g} / \mathrm{m}^{3}\right)$ \\
\hline MIT: & Minimum ingnition temperature (K) \\
\hline MIE: & Minimun ignition energy $(\mathrm{J})$ \\
\hline MWCNTs : & multiwalled carbon nanotubes \\
\hline $\mathrm{N}:$ & Number of Particles per unit of volume $\left(\# / \mathrm{m}^{3}\right)$ \\
\hline OEB & Occupational Exposure band \\
\hline $\mathrm{OEB}_{\mathrm{l}}$ & Occupational Exposure limit Band \\
\hline OHB: & Occupational Hazard band \\
\hline Sbet : & surface of the particle $\left(\mathrm{m}^{2}\right)$ \\
\hline SEM: & Scanning Electron Microscopy \\
\hline SWCNTs: & Single-walled carbon nanotubes \\
\hline $\mathrm{T}:$ & Temperature (K) \\
\hline TEM: & Transmission Electron Microscopy \\
\hline $\mathrm{V}_{\mathrm{p}}$ & Volume of the particle $\left(\mathrm{m}^{3}\right)$ \\
\hline Greek sym & \\
\hline$\rho:$ & density $\left(\mathrm{Kg} / \mathrm{m}^{3}\right)$ \\
\hline
\end{tabular}

REFERENCES

1999/92/EC; 1999. DIRECTIVE 1999/92/EC OF THE EUROPEAN PARLIAMENT AND OF THE COUNCIL of 16 December 1999 on minimum requirements for improving the safety and health protection of workers potentially at risk from explosive atmospheres (15th 
individual Directive within the meaning of Article 16(1) of Directive 89/391/EEC). Official Journal of the European Communities, L 23/57.

ANSES, December 2010. Development of a specific Control Banding Tool for Nanomaterials, Request $\mathrm{N}^{\circ} 2008-\mathrm{SA}-0407$ relating to Control Banding. French Agency for Food, Environmental and Occupational Health \& Safety (ANSES).

Baran, E., Özer, N., Hasirci, V., 2002. In vivo half life of nanoencapsulated L- asparaginase. J. Mat Sci: Mat in Med 13, 1113-1121.

Berge, T., W. F., Zwaert, A., Appelman, L.M., 1986. Concentration Time mortality response relationship of irritant systemic acting vapours and gases. J. Hazardous Materials. 13, 301309.

Bouillard, J., Vignes, A., Dufaud, O., Perrin, L., Thomas, D., 2010. Ignition and explosion risks of nanopowders. Journal of Hazardous Materials 181, 873-880.

Bouillard, J.F., E.;R'mili, B;Fleury, D;, 2011. Device for the characterization of the particulate release from combustion or thermal constraints upon materials containing nano-objects. INERIS, France,.

Brouwer, D.H., 2012. Control Banding Approaches for Nanomaterials. The Annals of Occupational Hygiene 56, 506-514.

Bunce, N.J., Remillard, J., 2003. Haber's rule: The search for quantitative relationships in Toxicology. Hum Ecol. Risk Assess 9, 973-985.

Cascone, M.G., Lazzeri, L., Carmignani, C., Zhu, Z., 2002. Gelatin nanoparticles produced by a simple W/O emulsion as delivery system for methotrexate. J Mat Sc: Mat in Med 13, 523526.

Cornelissen, R.J., F.; Van Broekhuizen, F., 2011. Guidance working safely with nanomaterials and products, the guide for employers and employees. Document 113. Amsterdam, the Netherlands: IVAM http://www.industox.nl/Guidance\%20on\%20safe\%20handling\%20nanomats\&products.pdf.

Dahoe, A.E., Cant, R.S., Pegg, M.J., Scarlett, B., 2001. On the transient flow in the 20-liter explosion sphere. Journal of Loss Prevention in the Process Industries 14, 475-487.

de Dianous, V., Fiévez, C., 2006. ARAMIS project: A more explicit demonstration of risk control through the use of bow-tie diagrams and the evaluation of safety barrier performance. Journal of Hazardous Materials 130, 220-233.

Delvosalle, C., Fievez, C., Pipart, A., Debray, B., 2006. ARAMIS project: A comprehensive methodology for the identification of reference accident scenarios in process industries. Journal of Hazardous Materials 130, 200-219.

Dufaud, O., Perrin, L., Traore, M., Chazelet, S., Thomas, D., Laurent, A., 2005. Poudres et Sécurité: Entre Explosions et humidité : Y a t il de l'eau dans le gaz ? Journées Poudres et sécurité

Eckoff, R.K., 2003. Dust explosions in the process industries. Gulf Professional Publishing, New-York.

Elgrabli, D., Floriani, M., Abella-Gallart, S., Meunier, L., Gamez, C., Delalain, P., Rogerieux, F., Boczkowski, J., Lacroix, G., 2008. Biodistribution and clearance of instilled carbon nanotubes in rat lung. Part Fibre Toxicol. 5, 20.

Ferrari, M., 2005. Cancer nanotechnology: opportunities and challenges. Nature Reviews. Nature Reviews: Cancer 5, 161-171.

Fleury, D.B., João A S ; Metz, Sébastien ; Bouillard, Jacques X; Brignon, Jean-Marc ;, 2011. Nanoparticle risk management and cost evaluation: a general framework. J. Phys.: Conf. Ser. 304, 012084

Gemeinhart, R.A., Luo, D., Saltzman, W.M., 2005. Cellular fate of modular DNA delivery system mediated by silica nanoparticles. Biotechn Prog 21, 532-537. 
Glor M. , 1988. Electrostatic hazards in powder handling. , in: Inc, J.W.S. (Ed.). Research Studies press Ltd.

Gowland, Richard, 2006. The accidental risk assessment methodology for industries (ARAMIS)/layer of protection analysis (LOPA) methodology: A step forward towards convergent practices in risk assessment? Journal of Hazardous Materials 130, 307-310.

Groso, A., Alke Petri-fink, Arnaud Magrez, Michael Riediker, and Thierry Meyer. , 2010. "Management of Nanomaterials Safety in Research Environment." Particle and Fibre Toxicology . 7, 40.

Hock, J.H.H.H.K., 2008. Precautionary Matrix for Synthethic Nanomaterials. Bern, Switzerland: Federal Office for Public Health and Federal Office for the Environment.

HSE, 2004. NANOMATERIALS - a risk to health at work? First International Symposium on Occupational Health Implications of Nanomaterials - Report of Presentations at Plenary and Workshop Sessions and Summary of Conclusions, HSE Workshops.

INNOVEST, August 29, 2005. Nanotechnology - Non-traditional Methods for Valuation of Nanotechnology Producers - Introducing the Innovest Nanotechnology Index for the Value Investor.

ISO/TS-27687, 2008. International Standards Organization, "Nanotechnologies Terminology and definitions for nano-objects - Nanoparticle, nanofibre and nanoplate.

ISO/TS-80004-1, 2010. Nanotechnologies- Vocabulary Part 1: Core terms. ISO/TS 800041:201O(E).

ISO/TS-80004-4;, 2011. Nanotechnologies- Vocabularly: Part 4: nanostructures materials. ISO/TS 80004-4:2011(E).

Kalkert, N., Schecker, H.-G., 1979. Theoretische Überlegungen zum Einfluß der Teilchengröße auf die Mindestzündenergie von Stäuben†. Chemie Ingenieur Technik 51, 1248-1249.

Kipp, J.E., 2004. The role of solid nanoparticle technology in the parental delivery of poorly water-soluble drugs. Int J Pharm. 284, 109-122.

Kneuer, C., Sameti, M., Bakowsky, U., Schiestel, T., Scirra, H., Schmidt, H., Lehr, C.M., 2000. A nonviral delivery system based on surface modified silica-nanoparticles can efficiently transfect cells in vitro. Bioconjug Chem 2000 11, 926-932.

Laurent, A., 2003. Sécurité des Procédés Chimiques - connaissances de base et méthodes d'analyse de risques. Chapitre 6 : Explosions de poussières. Tec\&Doc, Paris.

Le Nguyen, T., Adjadj, A., Chaumette, S., Bouchet, S., de Dianous, V., 2008. Evaluation des performances des Barrières Techniques de Sécurité (DCE DRA-73) Evaluation des Barrières Techniques de Sécurité - $\Omega 10$.

Marquart, H., Henri Heussen, Maaike Le Feber, Dook Noy, Erik Tielemans, Jody Schinkel, John West, and Doeke Van Der Schaaf. , 2008. "'Stoffenmanager', a Web-based Control Banding Tool Using an Exposure Process Model.” The Annals of Occupational Hygiene 52, 429-441.

Nandiyanto, A.B.D., Okuyama, K., 2011. Progress in developing spray-drying methods for the production of controlled morphology particles: From the nanometer to submicrometer size ranges. Advanced Powder Technology 22, 1-19.

NFPA, 1962. Fire Protection Handbook. National Fire Protection Association.

NIOSH - Centers for Disease Control and Prevention, 2005. Approaches to Safe Nanotechnology - An Information Exchange with NIOSH.

Oberdoester, G., Oberdorster, E., Oberdorster, J., 2005. Nanotoxicology : An Emerging Discipline evolving from Studies of Ultrafine Particles. Environmental Health Perspectives, 113, 823-839. 
OECD, 2008. List of Manufactured nanomaterials and List of Endpoints for Phase One of the OECD Testing Programme. Organisation for Economic Cooperation and Development ENV/JM/MONO(2008)13/REV.

Paik, S.Y., David M Zalk, and Paul Swuste. , 2008. "Application of a Pilot Control Banding Tool for Risk Level Assessment and Control of Nanoparticle Exposures." The Annals of Occupational Hygiene 52, 419-428.

Peter Van Broekhuizen, W.V.V., Willem-Henk streekstra, Paul Schulte and Lucas Reijnders, 2012. Exposure mimits for nanomarticles: Report of an International Workshop on Nanoreference values. Ann. Occup. Hyg. 56, 515-524.

Peukert W., 1996. Trends in solids process engineering (in German). . Chemie -IngenieurTechnik 66, 1254-1263.

Ravi, K., M. N., Sameti, M., Mohapatra, S.S., Kong, X., Lockey, R.F., Bakowsky, U., Lindenblatt, G., Schmidt, H., Lehr, C.M., 2004. Cationic silica nanoparticles as gene carriers: synthesis, characterization and transfection efficiency in vitro and in vivo. J. Nanosci. Nanotechnol. 4, 876-881.

Roy, I., Ohulchanskyy, T.Y., Bharali, D.J., Pudavar, H.E., Mistretta, R.A., Kaur, N., Prasad, P.N., 2005. Optimal tracking of organically modfied silica nanoparticles as DNA carriers: a nonviral, nanomedicine approach for gene delivery. Proc Natl Acad Sci USA 102, 297-284.

Salem, A.K., Searson, P.C., Leong, K.W., 2003. Multifunctional nanorods for gene delivery. Nat Mater 2, 668-671.

Salvi, O., Debray, B., 2006. A global view on ARAMIS, a risk assessment methodology for industries in the framework of the SEVESO II directive. Journal of Hazardous Materials 130, 187-199.

SCENIHR, 2005. Opinion on The appropriateness of existing methodologies to assess the potential risks associated with engineered and adventitious products of nanotechnologies Scenihr (Scientific Committee on Emerging and Newly Identified Health Risks) 7th plenary meeting of 28-29 September 2005. EU- Health \& Consumer Protection Directorate-General Directorate C - Public Health and Risk Assessment.

Seveso Directive, Council Directive 82/501/EEC on the major-accident hazards of certain industrial activities OJ No L 230 of 5 August 1982.

Traoré, M., Dufaud, O., Perrin, L., Chazelet, S., Thomas, D., 2009. Dust explosions: How should the influence of humidity be taken into account? Process Safety and Environmental Protection 87, 14-20.

Van Broekhuizen, P., Veelen, W.V., Willem-Henk , S., Paul, S., Lucas, R., 2012. Exposure limits for nanomarticles: Report of an International Workshop on Nano Reference Values. Ann. Occup. Hyg. 56, 515-524.

Van Duuren-Stuurman, B.S., R. Vink; Koen, J. M. Verbist; Henri, G. A. Heussen; Derk, H. Brouwer; Dinant, E. D. Kroese; Maikel, F. J. Van Niftrik; Erik, Tielemans;Wouter, Fransman; , 2012. "Stoffenmanager Nano Version 1.0: a Web-based Tool for Risk Prioritization of Airborne Manufactured Nano Objects.” The Annals of Occupational Hygiene 56, 525-541.

Veronesi, B., Haar, C., Lee, L., Oortgiesen, M., 2002. The surface charge of visible particuate matter predicts biological activation in Human Bronchial Epithelial Cells. Toxicology and Applaied Pharmacology 178, 144-154.

Veronesi, B., Oortgiesen, M., Carter, J.D., Delvin, R.B., 1999. "Particulate matter Initiates Inflammatory Cytokine Release by activation of Capsaicin and Acid Receptors in a human Bronchial Epithelial cell Line”. Toxilogy and applied Pharmacology 154, 106-115.

Vignes, A., Munoz, F., Bouillard, J., Dufaud, O., Perrin, L., Laurent, A., Thomas, D., 2012. Risk assessment of the ignitability and explosivity of aluminum nanopowders. Process Safety and Environmental Protection 90, 304-310. 
Wang, J., Chen, C., Liu, Y., Jiao, F., Li, W., Lao, F., Li, Y., Li, B., Ge, C., Zhou, G., Gao, Y., Zhao, Y., Chai, Z., 2008a. Potential neurological lesion after nasal instillation of TiO2 nanoparticles in the anatase and rutile crystal phases. Toxicology Letters 183, 72-80.

Wang, J., Liu, Y., Jiao, F., Lao, F., Li, W., Gu, Y., Li, Y., Ge, C., Zhou, G., Li, B., Zhao, Y., Chai, Z., Chen, C., 2008b. Time-dependent translocation and potential impairment on central nervous system by intranasally instilled TiO2 nanoparticles. Toxicology 254, 82-90.

Witschger, O., Fabries, J.-F., 2005a. Particules ultra-fines et santé au travail 1 Caractéristiques et effets potentiels sur la santé. Hygiène et sécurité du travail - Cahiers de notes documentaires INRS 2ème trimestre 2005, , 21-35.

Witschger, O., Fabries, J.-F., 2005b. Particules ultra-fines et santé au travail 2 - Sources et caractérisation de l'exposition. Hygiène et sécurité du travail - Cahiers de notes documentaires INRS 199, 37-54.

Yoo, H.S., Lee, J.E., Chung, H., Kwon, I.C., Jeong, S.Y., 2005. Self-assembled nanoparticles containing hydrophobically modified glycol chitosan for gene delivery. J Control Release 103, 235-243.

Zalk, D.M., Nelson, D.I., 2008. History and Evolution of Contol Banding: A review. Journal of Occupational and Environmental Hygiene 5, 330-346. 


\section{Nano-Evaluris- An Inhalation and Explosion Risk Evaluation Method for Nanoparticle Use: Part I Description of the methodology - Jacques Bouillard and Alexis Vignes}

\section{Table of tables}

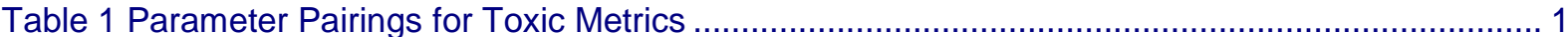

Table 2: Size dependent of Threshold limiting values (TLVs) ..................................................... 1

Table 3 Example of Proposed Inhalation OEB (Occupational Exposure Band 8 hours/day) ranking..... 2

Table 4 Accidental or short term Expositon Index ................................................................... 2

Table 5 Penetration Factors for typical Face Masks (BGIA)) ….............................................. 2

Table 6 Typical Personal Protective Equipment Performances ...................................................... 2

Table 7 Proposed score of the quantity of nanoparticle used (based on TNT scales) .............................. 3

Table 8 Classical Explosion violence index ..................................................................................... 3

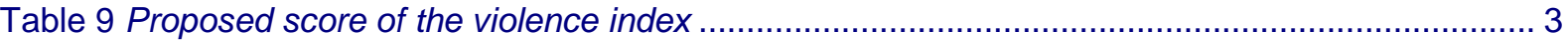

Table 10 Proposed score of the occurrence of the formation of an explosive atmosphere .................... 3

Table 11 Proposed score of the frequency of the presence of an ignition source .................................. 3

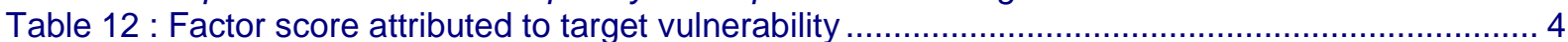

Table 13 Proposed risk reduction scores for safety prevention and protection barriers ....................... 4

Table 14 Proposed characterisation of priorities in relation to the risk score per process phase ........... 4

Table 1 Parameter Pairings for Toxic Metrics

\begin{tabular}{|l|l|l|l|}
\hline \multicolumn{1}{|c|}{ Toxic Metrics } & \multicolumn{3}{|c|}{$\begin{array}{l}\text { Basic parameters to be } \\
\text { considered }\end{array}$} \\
\hline $\begin{array}{l}\text { Number concentration of a mean } \\
\text { size }\end{array}$ & $\mathrm{N}$ & $\mathrm{d}_{\mathrm{p}}$ & \\
\hline Surface concentration : $\mathrm{C}_{\mathrm{s}}$ & $\mathrm{N}$ & $\begin{array}{l}\mathrm{d}_{\mathrm{p}}{ }^{2} \text { or } \\
\mathrm{B}_{\mathrm{Bet}}\end{array}$ & \\
\hline Mass Concentration : $\mathrm{C}_{\mathrm{m}}$ & $\mathrm{N}$ & $\mathrm{d}_{\mathrm{p}}{ }^{3}$ & $\rho$ \\
\hline
\end{tabular}

Table 2: Size dependent of Threshold limiting values (TLVs)

\begin{tabular}{|l|c|c|}
\hline Types of particles & Microscale (1 $\mathrm{\mu m})$ & Nanoscale (100 $\mathrm{nm})$ \\
\hline $\begin{array}{l}\mathrm{TLV} \\
\text { (threshold } \\
\text { values) }\end{array}$ & $\mathrm{mg} / \mathrm{m} 3)$ \\
\hline
\end{tabular}


Table 3 Example of Proposed Inhalation OHB/OEB, (Occupational Exposure Band 8 hours/day) ranking.

\begin{tabular}{|c|c|c|c|c|c|c|c|c|c|}
\hline $\mathrm{OHB}$ & 0 & 1 & 2 & 3 & 4 & 5 & (6) & (7) & ---- \\
\hline Hazard & & Low & Moderate & Potent & \multicolumn{5}{|c|}{ Highly Potent } \\
\hline $\begin{array}{l}\text { Tentative } \\
\text { Exposure } \\
\text { Threshold } \\
\text { Concentration } \\
\text { in Air } \\
\text { OEB } \\
\left(\mu \mathrm{g} / \mathrm{m}^{3}\right)^{\prime \prime}\end{array}$ & $\begin{array}{r}>50 \\
00\end{array}$ & $\begin{array}{r}>1000- \\
5000<\end{array}$ & $\begin{array}{l}>100- \\
1000<\end{array}$ & $\begin{array}{l}>10- \\
100<\end{array}$ & $\begin{array}{l}>1- \\
10<\end{array}$ & $\begin{aligned}>0.1- \\
1<\end{aligned}$ & $\begin{array}{r}>0.010 \\
.1<\end{array}$ & $\begin{array}{r}>0.001- \\
0.01<\end{array}$ & ------ \\
\hline $\begin{array}{l}\text { Equivalent } \\
\text { label } \\
\text { (Dir 98/24, } \\
\text { 99/45, 67/548 } \\
\text { (Still } \\
\text { application) in }\end{array}$ & & $\begin{array}{c}\mathrm{Xi} \\
\text { (irritant ) }\end{array}$ & $\begin{array}{l}\text { Xn } \\
\text { (noxious) }\end{array}$ & $\mathrm{T}$ & & & ------ $T^{+}$ & & \\
\hline $\begin{array}{l}\text { GHS : } \quad \text { CE } \\
n^{\circ} 1272 / 2008\end{array}$ & & & & & & & & & \\
\hline
\end{tabular}

Table 4 Accidental or short term Expositon Index

\begin{tabular}{|l|l|l|l|l|}
\hline Exposure times/day & Accidental & $<\mathbf{5}$ min & $\mathbf{5 - 4 5} \mathbf{m i n}$ & $\mathbf{4 5} \mathbf{~ m i n ~} \mathbf{8} \mathbf{~ h}$ \\
\hline If :(frequency index) & $\begin{array}{l}\text { To be determined } \\
\text { for each case } \\
\text { (Usually very small) }\end{array}$ & -2 & -1 & 0 \\
\hline
\end{tabular}

Table 5 Penetration Factors for typical Face Masks (BGIA))

\begin{tabular}{|l|l|l|}
\hline Type of filter media & Penetration & $\begin{array}{l}\text { Protection Index } \\
\text { (lproti) }\end{array}$ \\
\hline P1 & $5 \%$ & $1:\left(10^{-1)}\right.$ \\
\hline P2 & $0.2 \%$ & $2:\left(10^{-2}\right)$ \\
\hline P3 & $0.01 \%$ & $3:\left(10^{-3}\right)$ \\
\hline
\end{tabular}

Table 6 Typical Personal Protective Equipment Performances

\begin{tabular}{|l|l|l|l|}
\hline Type of Suits & Class Type & Penetration Performance & $\begin{array}{l}\text { Equivalent } \\
\text { Protection } \\
\text { index - Iproti }\end{array}$ \\
\hline $\begin{array}{l}\text { Ventilated Pressurized } \\
\text { Suits (Sperian) }\end{array}$ & Class 1 & $<5 \mathrm{E}-4$ & 3 \\
\hline & Class 2 & $<2 \mathrm{E}-4$ & 3.5 \\
\hline & Class 3 & $<1 \mathrm{E}-4$ & 4 \\
\hline & Class 4 & $<5 \mathrm{E}-5$ & 4.5 \\
\hline & Class 5 & $<2 \mathrm{E}-5$ & 5 \\
\hline $\begin{array}{l}\text { Non Ventilated Suits } \\
\text { (Sperian) }\end{array}$ & Class 1 & $<2 \mathrm{E}-1$ & 1 \\
\hline & & $<2 \mathrm{E}-2$ & 2 \\
\hline & Class 2 & $<2 \mathrm{E}-3$ & 3 \\
\hline
\end{tabular}


Table 7 Proposed score of the quantity of nanoparticle used (based on TNT scales)

\begin{tabular}{|c|c|}
\hline $\begin{array}{c}\text { Quantity } \\
\text { Score }\end{array}$ & $\begin{array}{c}\text { TNT Equivalent } \\
\text { Quantity (Kg) }\end{array}$ \\
\hline $\mathbf{1}$ & $>0-0,005$ \\
\hline $\mathbf{2}$ & $0.005-0,05$ \\
\hline $\mathbf{3}$ & $0,05-0.5$ \\
\hline $\mathbf{4}$ & $0,5-1.5$ \\
\hline $\mathbf{5}$ & $1,5-3$ \\
\hline
\end{tabular}

Table 8 Classical Explosion violence index

\begin{tabular}{|l|l|}
\hline St Class & Kst (bar.m. $\left.\mathbf{s}^{-1}\right)$ \\
\hline 0 & 0 \\
\hline 1 & $1-200$ \\
\hline 2 & $201-300$ \\
\hline 3 & $>300$ \\
\hline
\end{tabular}

Table 9 Proposed score of the violence index

\begin{tabular}{|l|l|}
\hline Score & Kst (bar.m.s \\
\hline 0 & 0 \\
\hline 1 & $>0-200$ \\
\hline 2 & $201-300$ \\
\hline$\underline{3}$ & $301-400$ \\
\hline$\underline{4}$ & $401-500$ \\
\hline$\underline{5}$ & $501-600$ \\
\hline$\underline{6}$ & $601-700$ \\
\hline $7-$ etc & $701-$ etc \\
\hline
\end{tabular}

Table 10 Proposed score of the occurrence of the formation of an explosive atmosphere (See ATEX Directive 1999/92/EC)

\begin{tabular}{|l|l|l|}
\hline Score & ATEX zones & Classification criteria \\
\hline $\mathbf{0}$ & No zone & No presence \\
\hline $\mathbf{1}$ & 22 & Unlikely in normal operation and only for short periods \\
\hline $\mathbf{2}$ & 21 & Occasionally likely in normal operation \\
\hline $\mathbf{3}$ & 20 & Frequently likely or for long periods or continuously \\
\hline
\end{tabular}

Table 11 Proposed score of the frequency of the presence of an ignition source

\begin{tabular}{|l|l|}
\hline Score & Probability of presence of the ignition source \\
\hline $\mathbf{0}$ & No ignition sources \\
\hline $\mathbf{1}$ & External accidental source or a natural event (eg lightning) \\
\hline $\mathbf{2}$ & Ignition source due to a malfunction, a wear, a handling error (eg electric stoppage) \\
\hline $\mathbf{3}$ & $\begin{array}{l}\text { Presence due to maintenance's operations (eg hot spot working) } \\
\text { Ignition source due to static electricity } \\
\text { (eg load of organic material or inflammable materials) } \\
\text { Occasional operation (eg presence of accumulator charge port, add-on heating } \\
\text { appliance) }\end{array}$ \\
\hline
\end{tabular}




\begin{tabular}{|l|l|}
\hline $\mathbf{4}$ & $\begin{array}{l}\text { Occasional presence due to the process } \\
\text { Occasional presence not due to the process (eg smoker) }\end{array}$ \\
\hline $\mathbf{5}$ & Permanent presence of an ignition source (eg hot surface in the process' equipment) \\
\hline
\end{tabular}

Table 12 : Factor score attributed to target vulnerability

\begin{tabular}{|l|l|}
\hline Presence of workers & V \\
\hline Yes & 1 \\
\hline No & 0 \\
\hline
\end{tabular}

Table 13 Proposed risk reduction scores for safety prevention and protection barriers

\begin{tabular}{|c|c|}
\hline Score & Level of confidence of the barriers \\
\hline $\mathbf{4}$ & High level of confidence \\
\hline $\mathbf{3}$ & Medium Level of confidence \\
\hline $\mathbf{2}$ & Low Level of confidence \\
\hline $\mathbf{1}$ & Inefficient \\
\hline
\end{tabular}

Table 14 Proposed characterisation of priorities in relation to the risk score per process phase

\begin{tabular}{|c|c|}
\hline $\begin{array}{c}\text { Risk } \\
\text { score/nanoparticle/operation }\end{array}$ & Priority \\
\hline$<10$ & Low \\
\hline $\mathbf{1 0 - 1 2 0}$ & Medium \\
\hline$>120$ & High \\
\hline
\end{tabular}




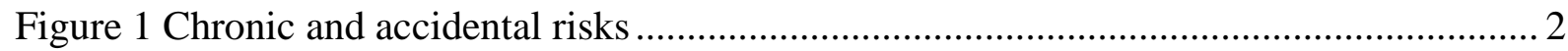

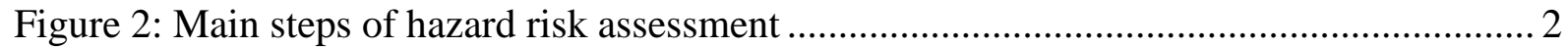

Figure 3 Health risk evaluation process for chronic exposure........................................... 3

Figure 4 General Accidental risk assessment flowchart ..................................................... 3

Figure 5 Evaluation of the toxic risk due to inhalation..................................................... 4

Figure 6 Inflammatory response from $20-250 \mathrm{~nm}$ Anatase $\mathrm{TiO}_{2}$ particles (24 h Intratracheal

instillation) (Oberdoester et al., 2005) .............................................................................. 4

Figure 7 Typical Comparison of $\mathrm{pH}$ mass titration between nano and microsized $\mathrm{TiO}_{2}$

particles

Figure 8 Proposed pictogram to inform users and operators of the potential presence of nanoparticles.

Figure 9 Typical emission concentration from a typical piece of Containment Equipment (ie Buck valves of GEA Technologies) used in the pharmaceutical industry with its respective Iproe emission index. Recall that emission is of the order of $10^{\text {Iproe }}$, which becomes smaller as Iproe is more negative.

Figure 10 Typical ventilated (left) and non ventilated (right) Personal Protective suits of respectively ranging below 1.2E-5 and below 5 E-4 penetration performance (Sperian data). 6 Figure 11: Construction of a risk analysis fault tree to identify the possible prevention barriers on a particular branch to reduce potential release of NP.

Figure 12 implementation of safety barriers to reduce the risk to an acceptable level ............. 7

Figure 13 Incorporation of MWCNT into a polymer matrix (polyamide PA6) in order to considerably reduce potential nanoparticulate emissions of MWCNTs in air. Left top:

MWCNT agglomerates viewed by (SEM) microscopy, left bottom, surface structures of agglomerates viewed by (TEM) electronic microscopy. This approach is a typical example of

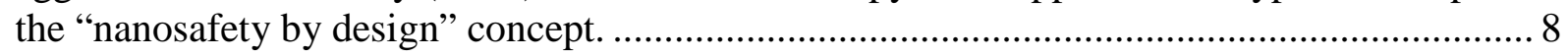

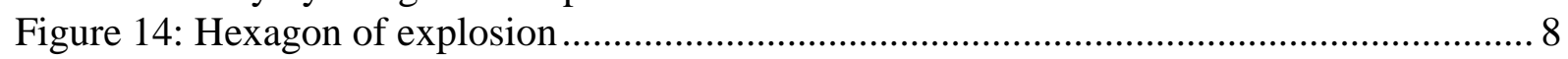

Figure 15: Main steps in order assess explosion risk. ......................................................... 9

Figure 16: Summary of the main steps leading to the determination of the severity score ..... 10

Figure 17: Summary of the main steps leading to the determination of the explosion

probability score 

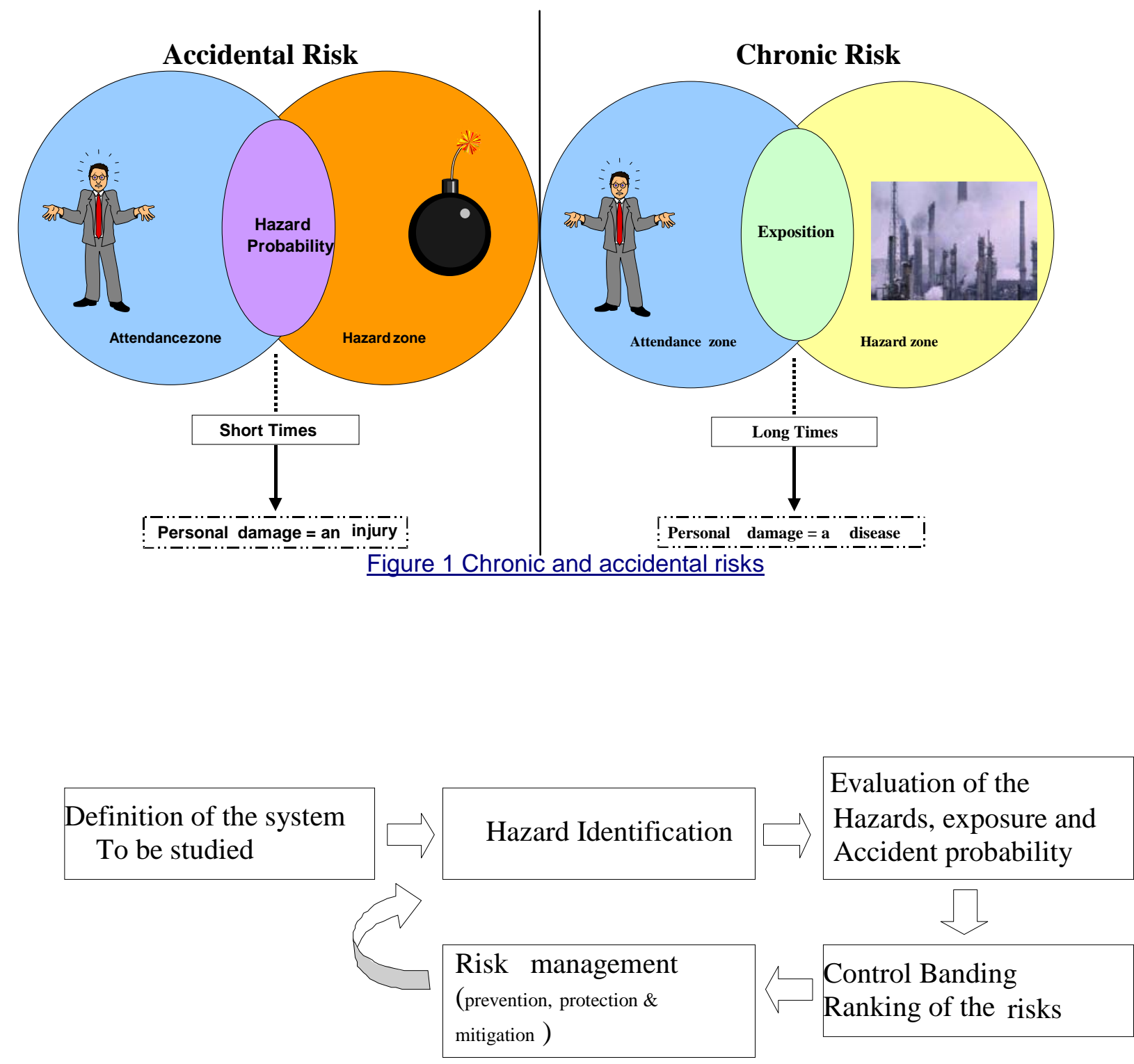

Figure 2: Main steps of hazard risk assessment 


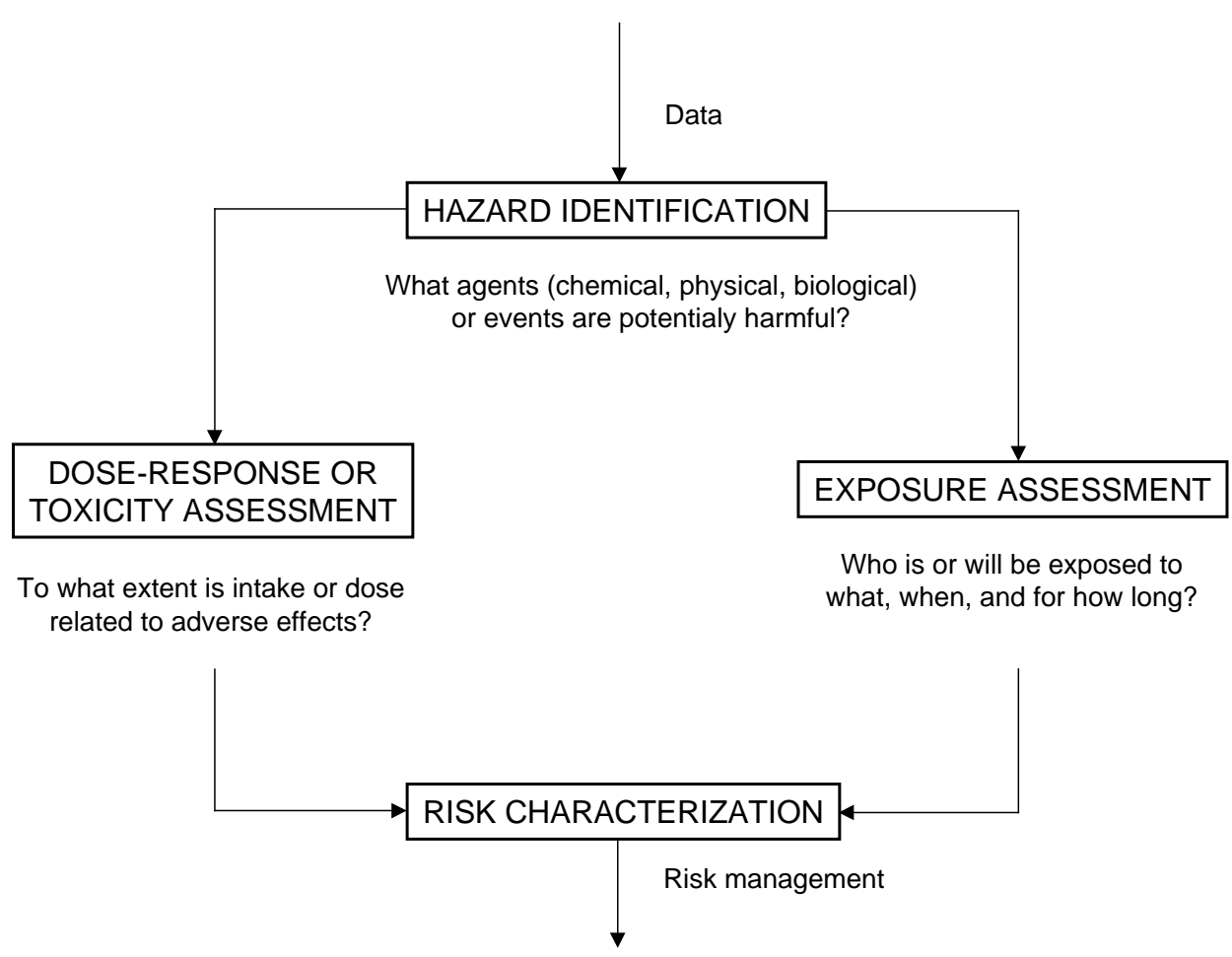

Figure 3 Health risk evaluation process for chronic exposure

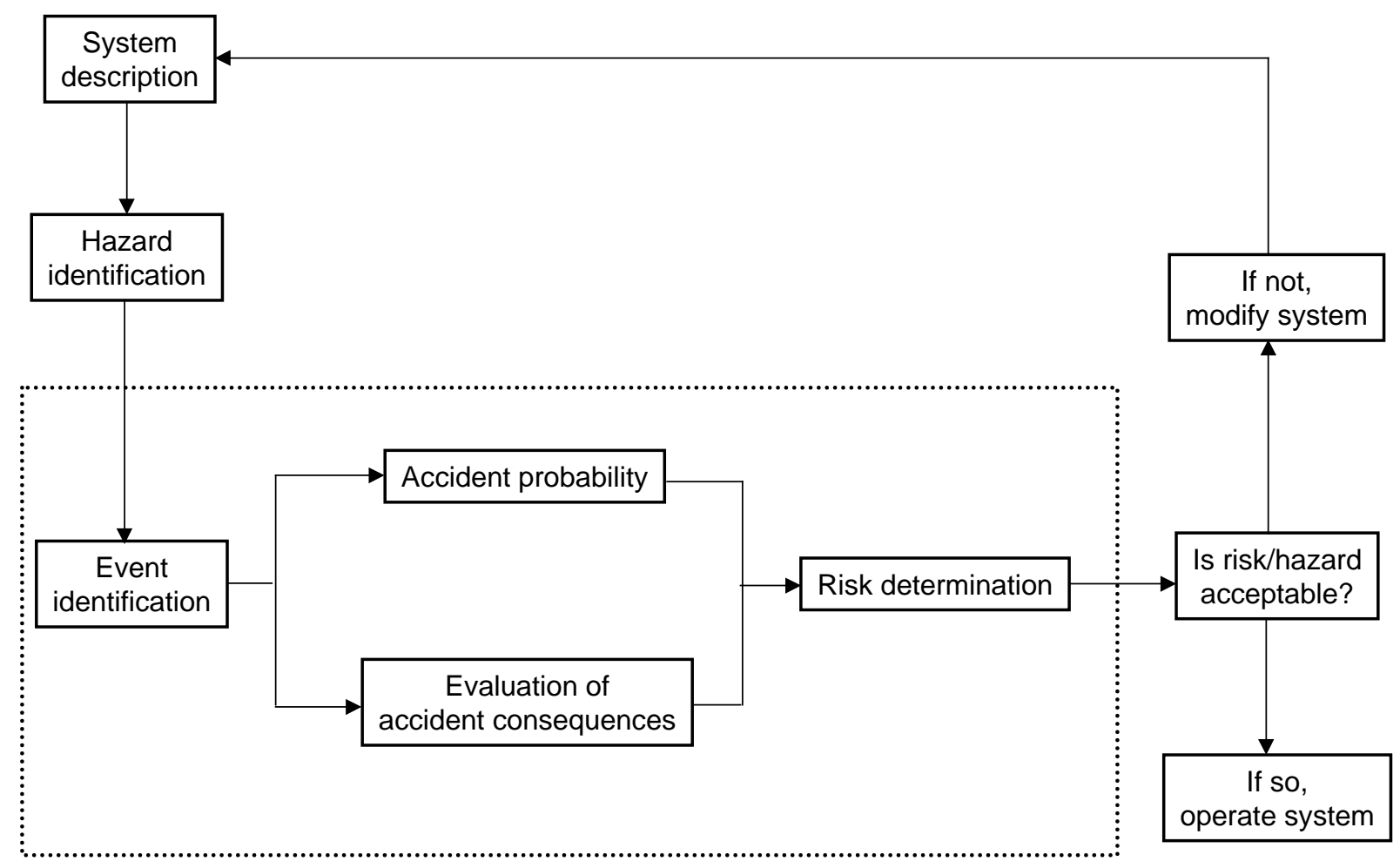

Figure 4 General Accidental risk assessment flowchart 


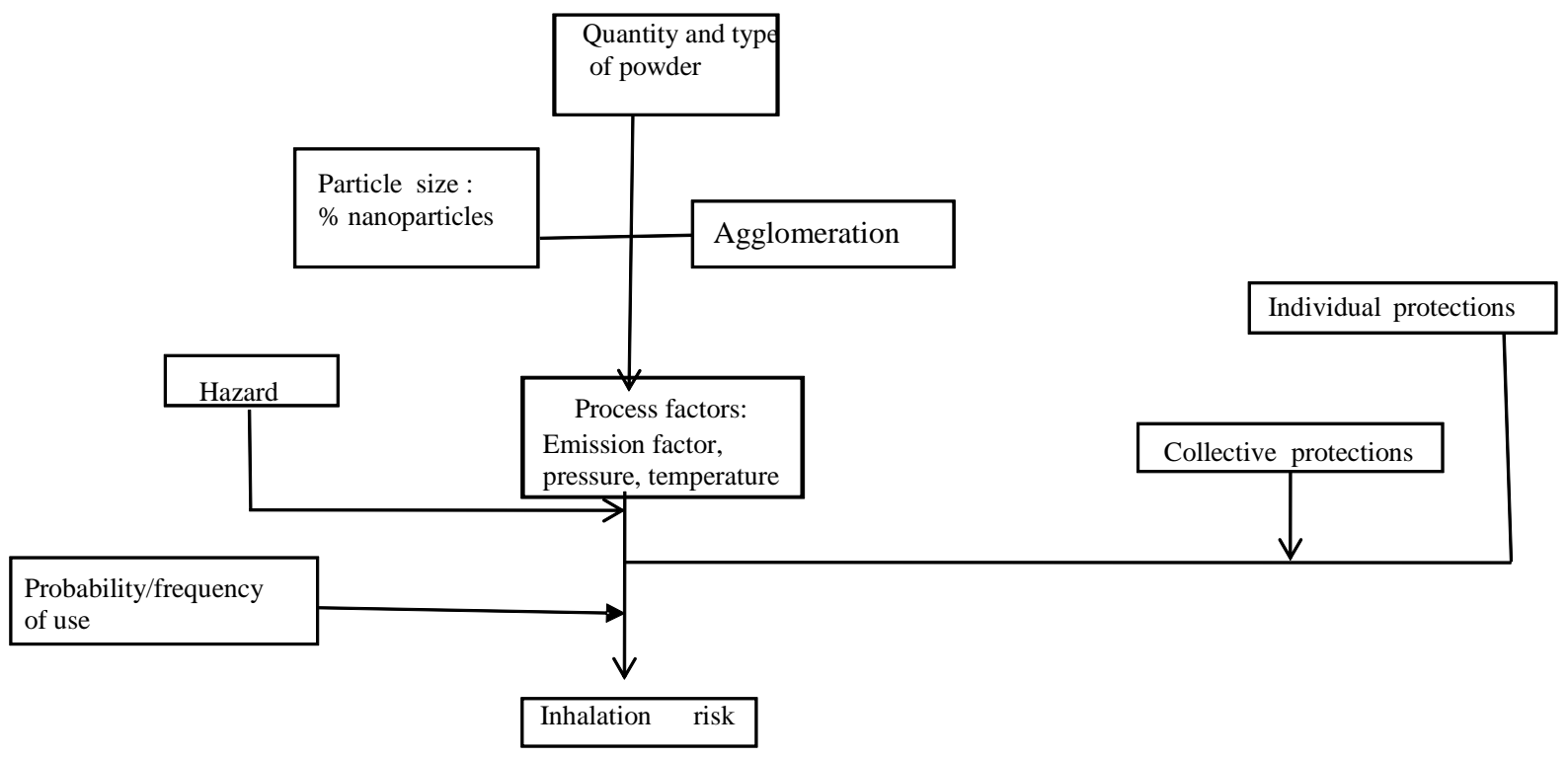

Figure 5 Evaluation of the toxic risk due to inhalation
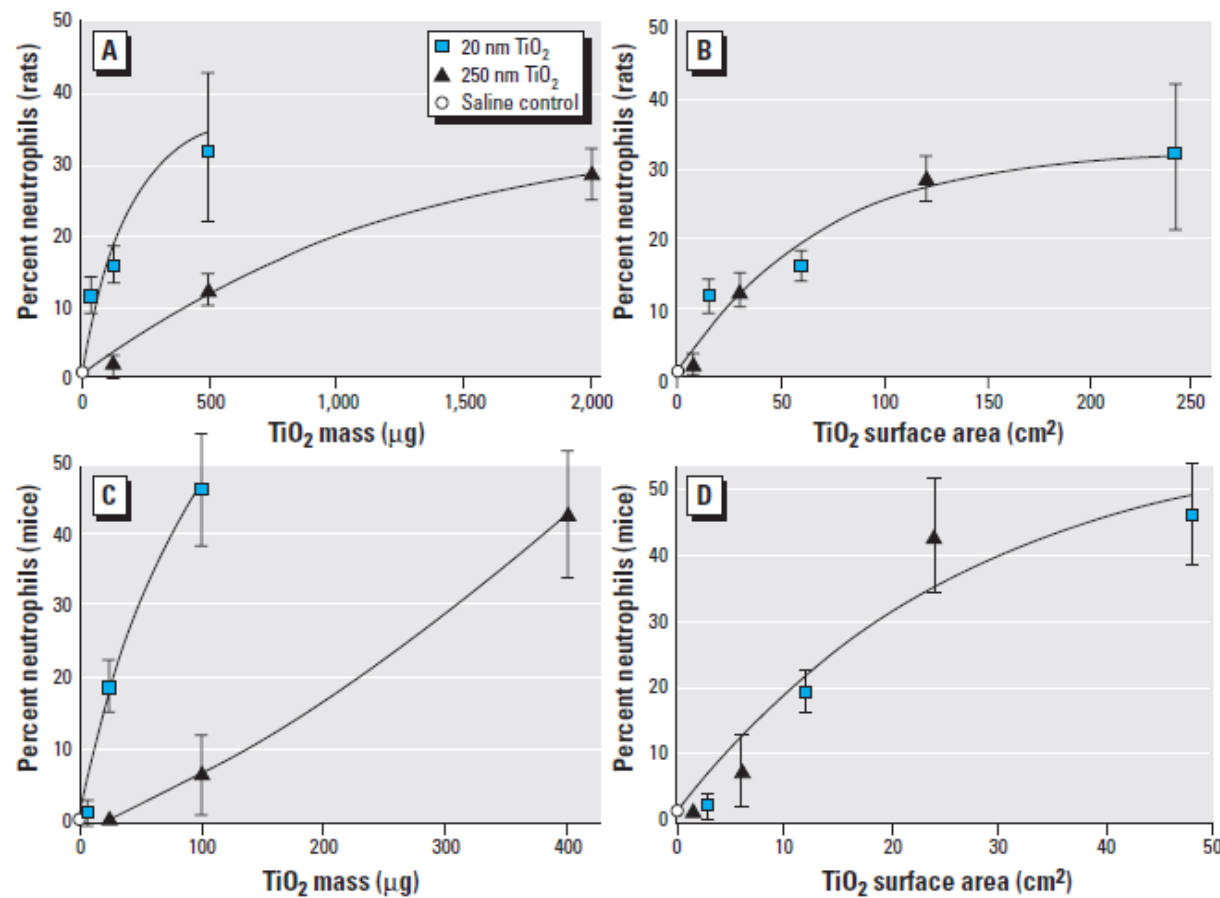

Figure 6 Inflammatory response from 20-250 nm Anatase $\mathrm{TiO}_{2}$ particles (24 h Intratracheal instillation) (Oberdoester et al., 2005) 


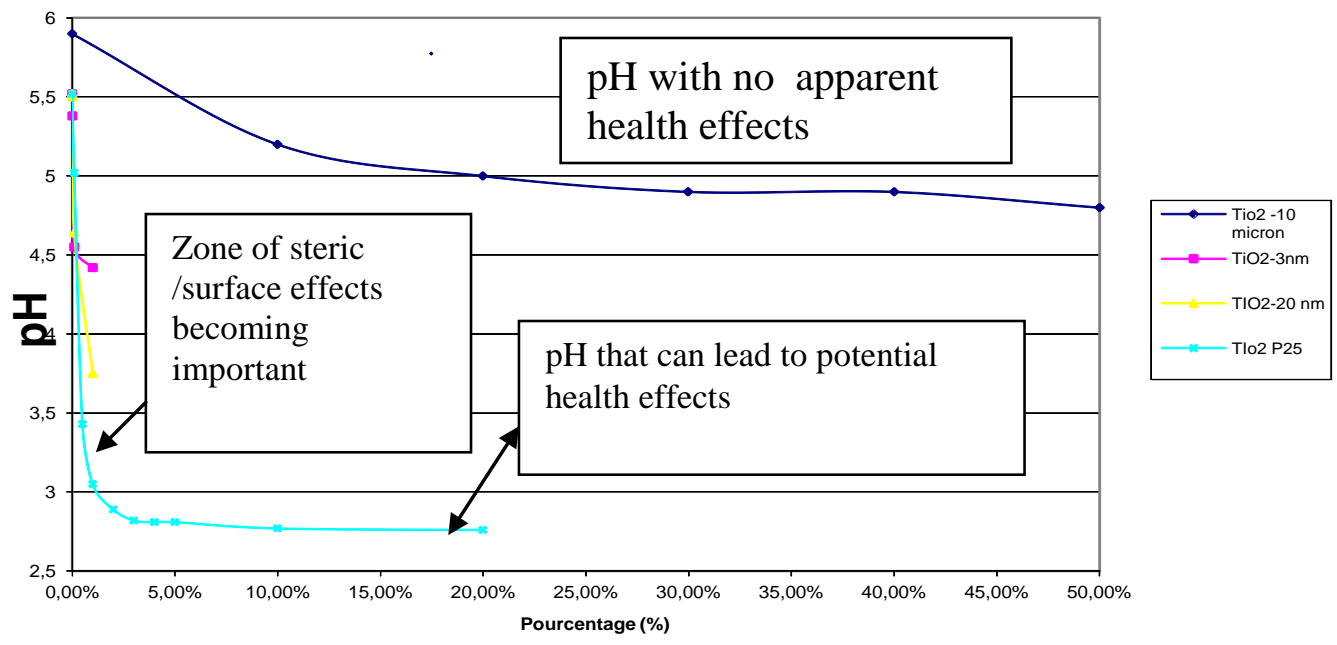

Figure 7 Typical Comparison of pH mass titration between nano and microsized $\mathrm{TiO}_{2}$ particles

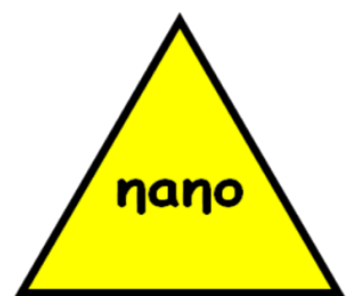

Figure 8 Proposed pictogram to inform users and operators of the potential presence of nanoparticles 


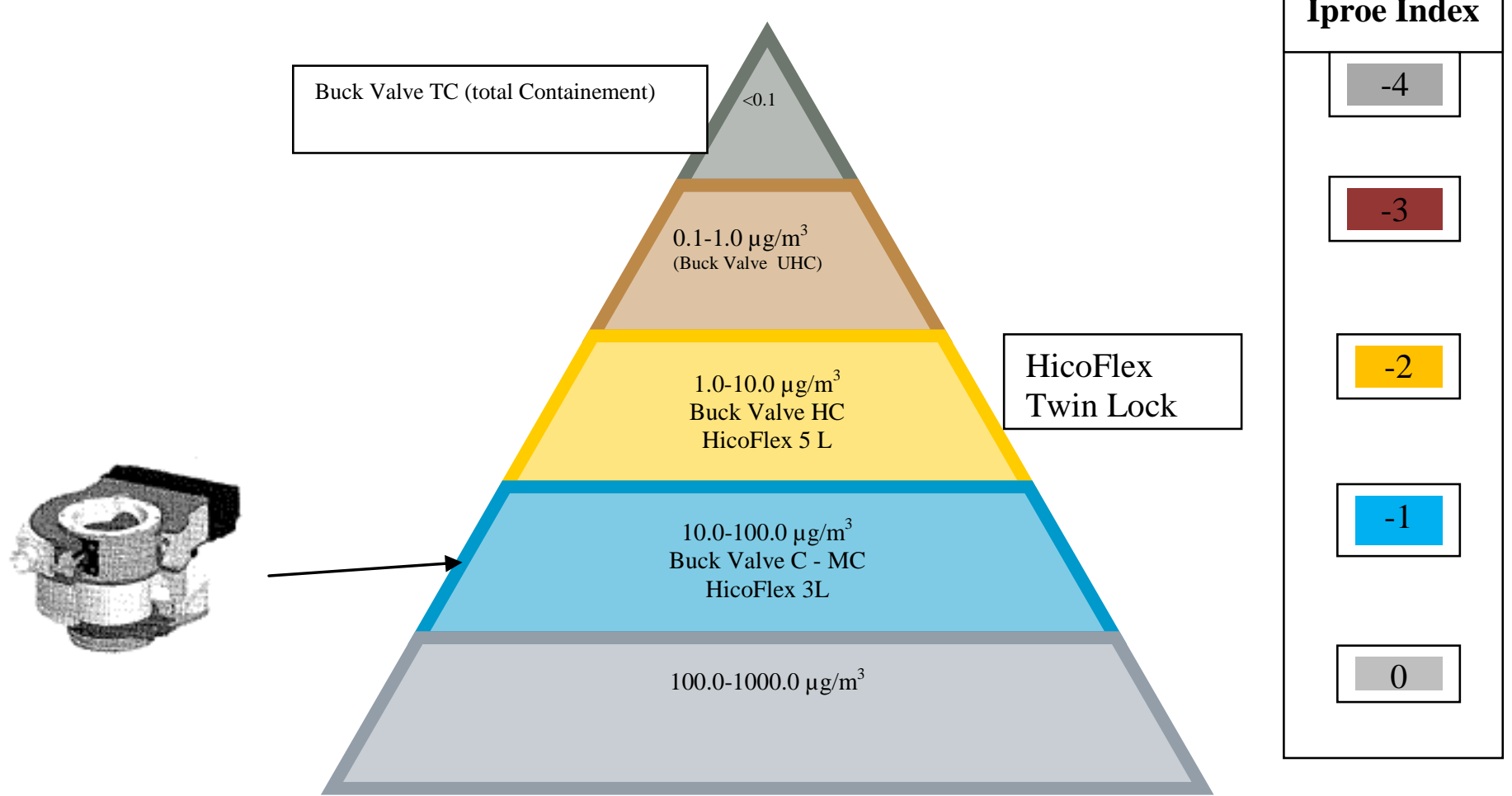

Figure 9 Typical emission concentration from a typical piece of Containment Equipment (ie Buck valves of GEA Technologies) used in the pharmaceutical industry with its respective Iproe emission index. Recall that emission is of the order of $10^{\text {Iproe }}$, which becomes smaller as Iproe is more negative.
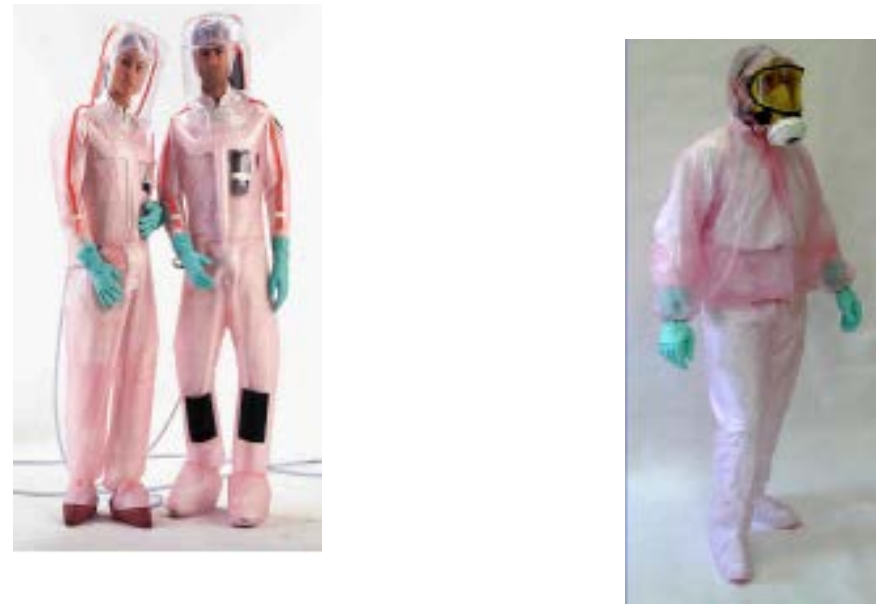

Figure 10 Typical ventilated (left) and non ventilated (right) Personal Protective suits of respectively ranging below 1.2E-5 and below 5 E-4 penetration performance (Sperian data) 


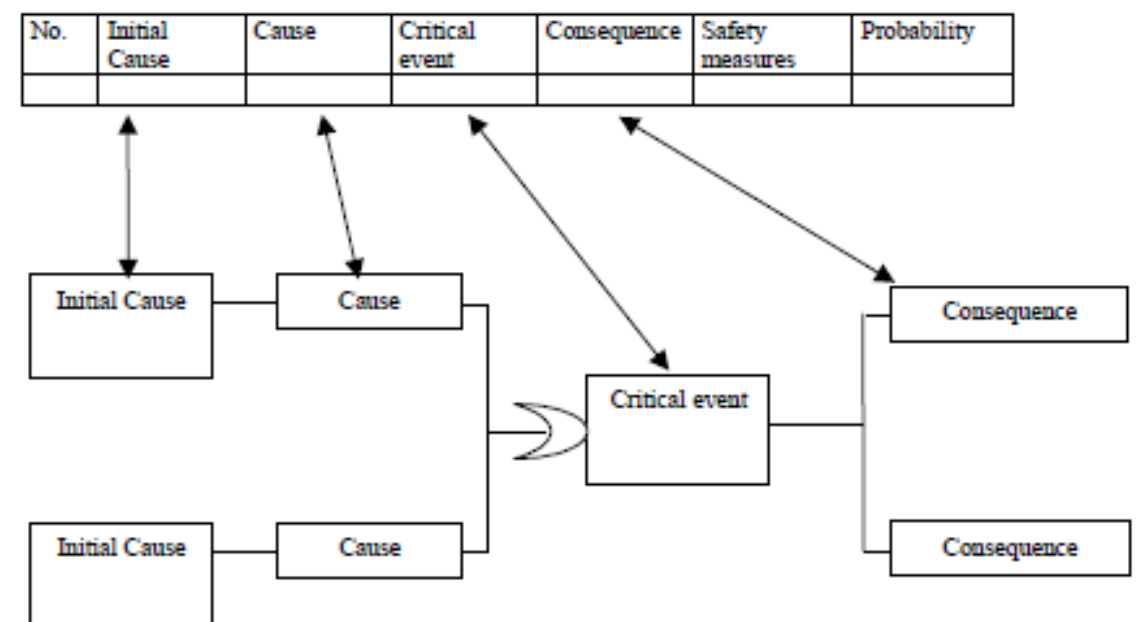

Figure 11: Construction of a risk analysis fault tree to identify the possible prevention barriers on a particular branch to reduce potential release of NP
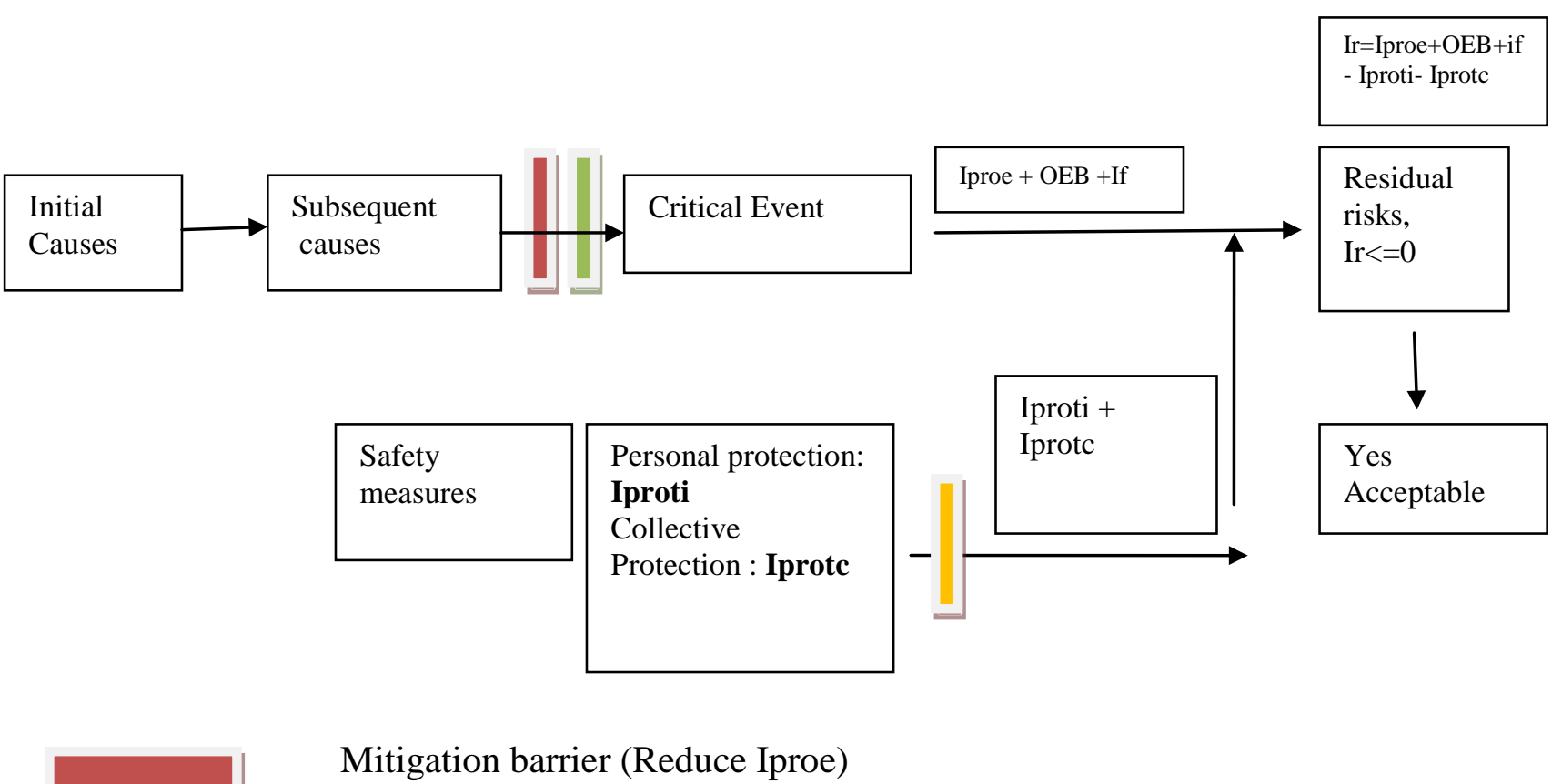

Mitigation barrier (Reduce Iproe)

Prevention barrier (Reduce Iproe and If)

Individual and collective Protection Barrier (increase Iprotc and Iproti)

Figure 12 implementation of safety barriers to reduce the risk to an acceptable level 

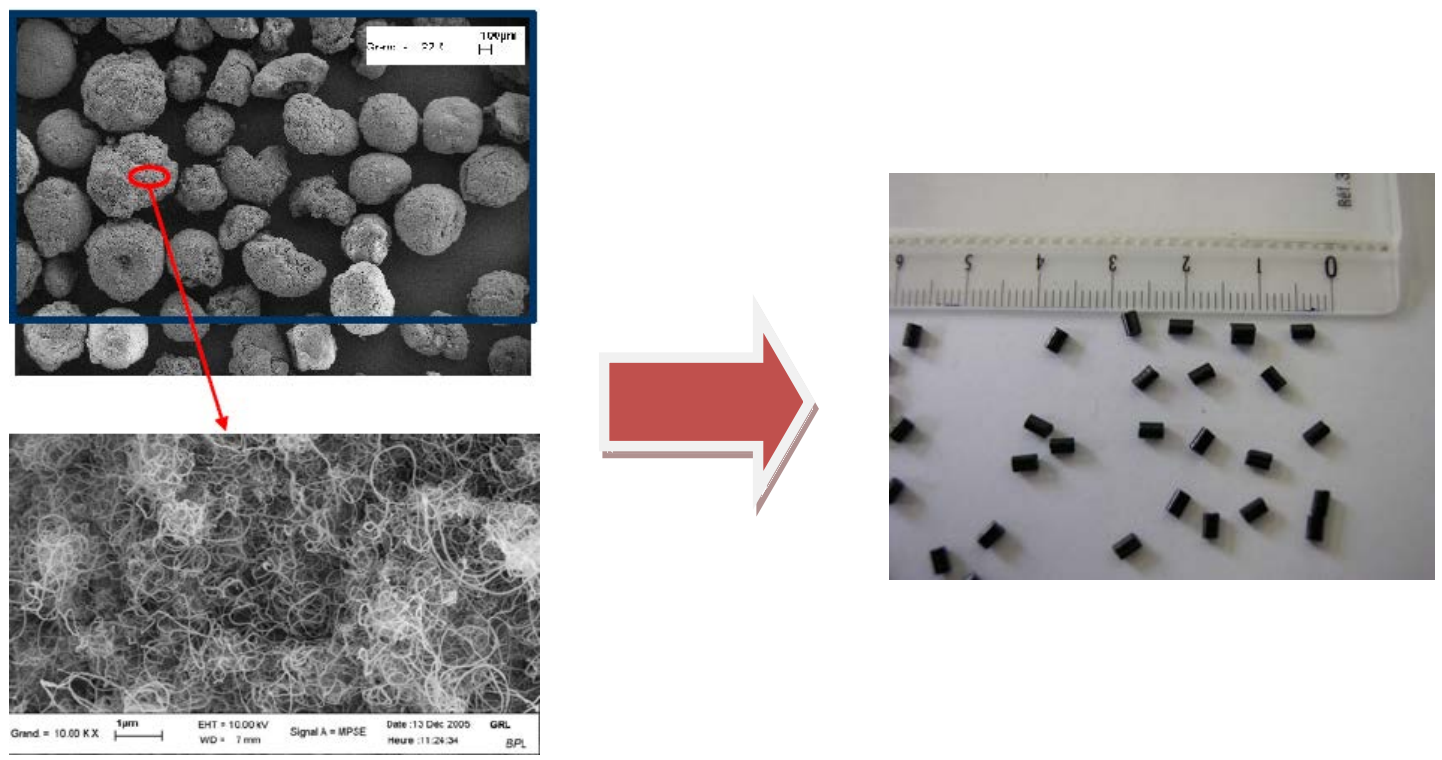

MWCNT agglomerates : Top viewed by scanning electronic microscopy (SEM) and bottom: surface structure

Final Nanosecured

Nanomaterial Product (PA6

using TEM view

Figure 13 Incorporation of MWCNT into a polymer matrix (polyamide PA6) in order to considerably reduce potential nanoparticulate emissions of MWCNTs in air. Left top: MWCNT agglomerates viewed by (SEM) microscopy, left bottom, surface structures of agglomerates viewed by (TEM) electronic microscopy. This approach is a typical example of the "nanosafety by design" concept.

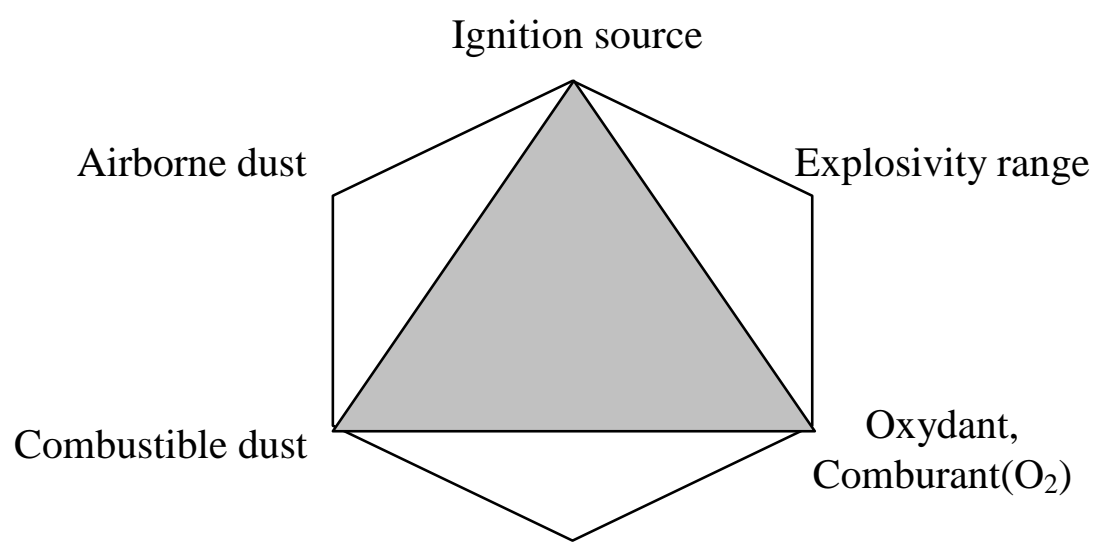

Confinement

Figure 14: Hexagon of explosion 
TARGET VULNERABILITY :

WORKER EXPOSURE
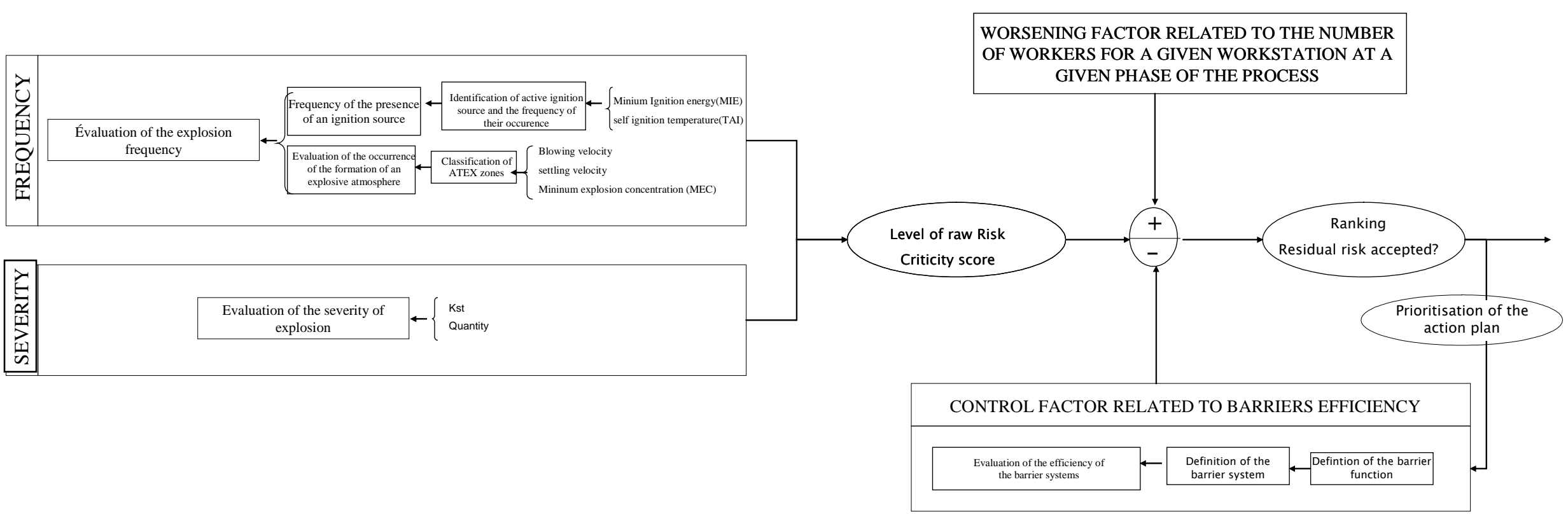

Figure 15: Main steps in order assess explosion risk. 


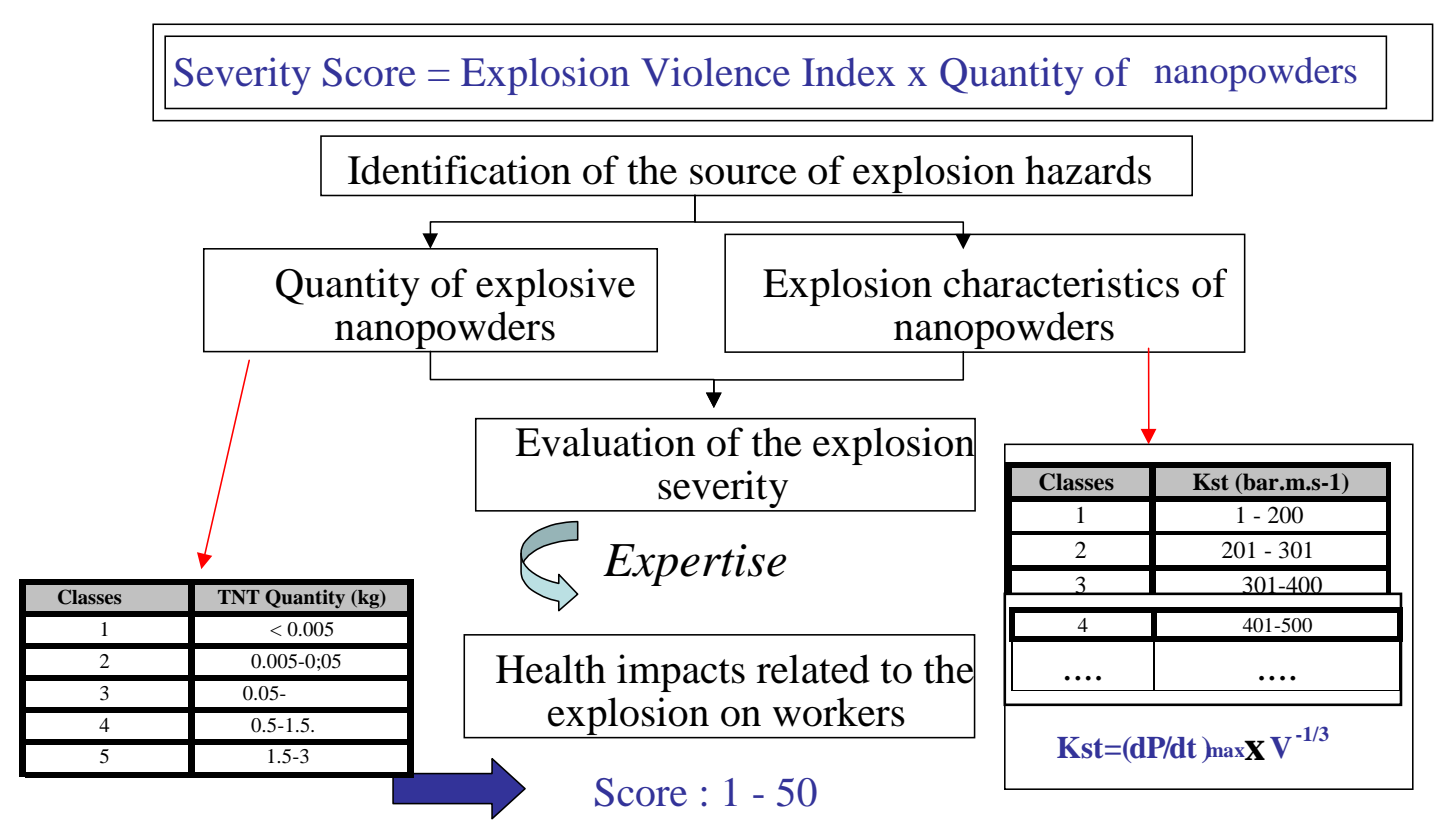

Figure 16: Summary of the main steps leading to the determination of the severity score

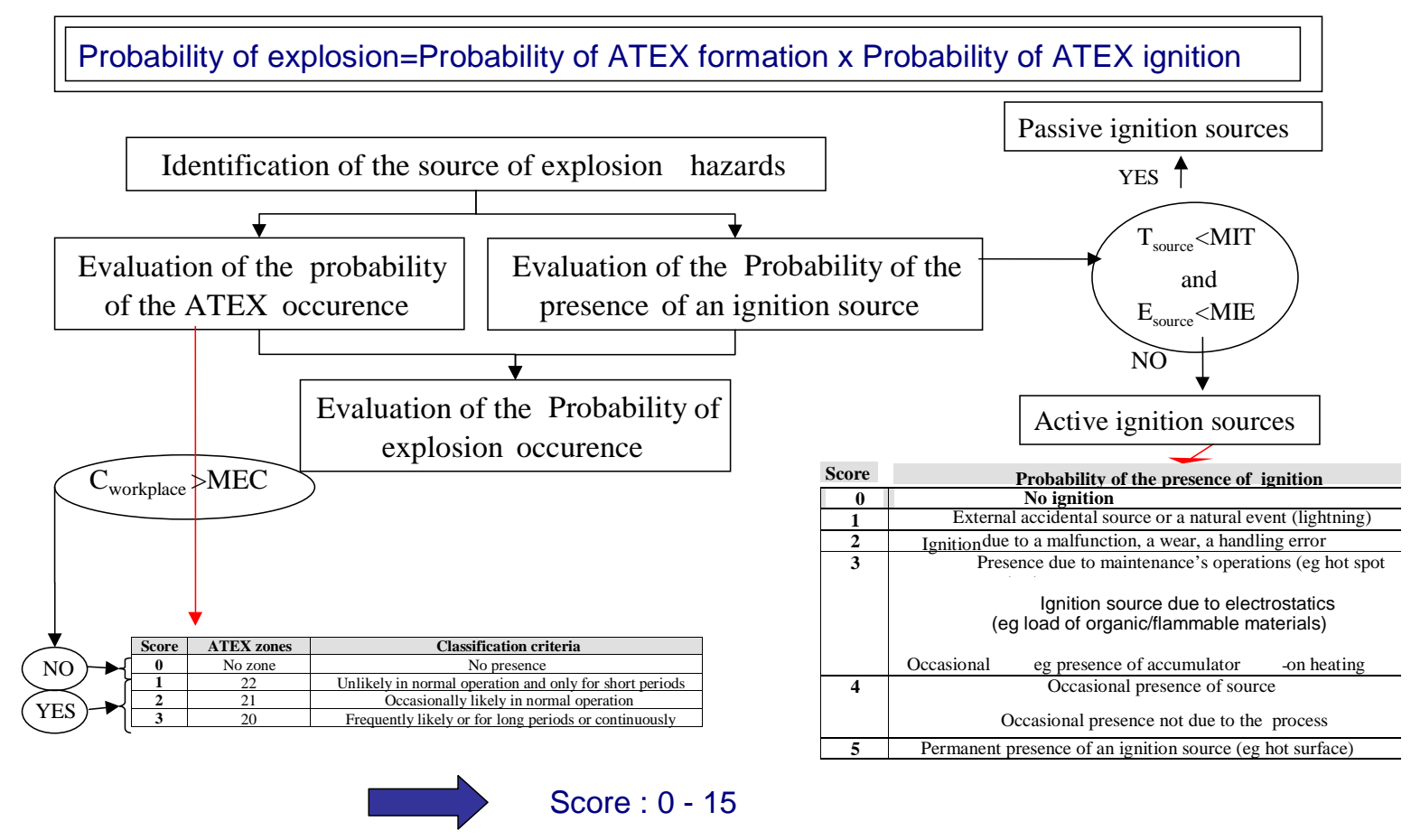

Figure 17: Summary of the main steps leading to the determination of the explosion probability score 